\title{
WestVirginiaUniversity
}

THE RESEARCH REPOSITORY @ WVU

Graduate Theses, Dissertations, and Problem Reports

2004

\section{Parametric modeling and analysis of structural bonded joints}

\author{
Sailaja Malladi \\ West Virginia University
}

Follow this and additional works at: https://researchrepository.wvu.edu/etd

\section{Recommended Citation}

Malladi, Sailaja, "Parametric modeling and analysis of structural bonded joints" (2004). Graduate Theses, Dissertations, and Problem Reports. 1446.

https://researchrepository.wvu.edu/etd/1446

This Thesis is protected by copyright and/or related rights. It has been brought to you by the The Research Repository @ WVU with permission from the rights-holder(s). You are free to use this Thesis in any way that is permitted by the copyright and related rights legislation that applies to your use. For other uses you must obtain permission from the rights-holder(s) directly, unless additional rights are indicated by a Creative Commons license in the record and/ or on the work itself. This Thesis has been accepted for inclusion in WVU Graduate Theses, Dissertations, and Problem Reports collection by an authorized administrator of The Research Repository @ WVU. For more information, please contact researchrepository@mail.wvu.edu. 


\title{
PARAMETRIC MODELING AND ANALYSIS OF STRUCTURAL BONDED JOINTS
}

\author{
Sailaja Malladi \\ Thesis submitted to the \\ College of Engineering and Mineral Resources \\ at West Virginia University \\ in partial fulfillment of the requirements \\ for the degree of \\ Master of Science \\ in \\ Mechanical Engineering \\ Jacky C. Prucz, Ph.D., Chair \\ Samir Shoukry, Ph.D., \\ Kenneth H. Means, Ph.D.,
}

Department of Mechanical and Aerospace Engineering Morgantown, West Virginia

2004

Keywords: Bonded Joints, ANSYS, Closed Form Model, Finite Element. 


\title{
ABSTRACT \\ Parametric Modeling and Analysis of Structural Bonded Joints Sailaja Malladi
}

\begin{abstract}
A closed form model of a double lap bonded joint based on the Hart-Smith Model is considered. An extensional link is added to the inner adherend in order to minimize the magnitude of the shear distribution in the adhesive along the overlap length and equations are formulated for this new model. Various parametric studies are performed on the closed form model to observe their effect on the behavior of the shear stress distribution in the adhesive. Overlap length, stiffness of the extensional link, thickness of the adhesive and stiffness of the adherends are varied in the parametric study.
\end{abstract}

A 2D finite element model is built using ANSYS 6.1 and is validated by the closed form model. The finite element model thus validated can be used for any complex geometry of the adherends and adhesive. The outer adherends that are tapered at an angle $45^{\circ}$ and a spew fillet inclusion in the adhesive are the two main types of joint configurations that are considered in the parametric studies of the finite element model.

The shear stress distribution in the adhesive is observed to be non linear. It is also observed that the shear stress distribution in the adhesive becomes uniform along the overlap length as the thickness of the adhesive increases. The effects of extensional link on the single lap and double lap bonded joints are compared. It is observed that the maximum stress in the double lap and single lap joint configurations has decreased considerably with addition of extensional link to the joint. 
This thesis is dedicated to Mummy and Sunni... 


\section{ACKNOWLEDGEMENT}

It is a pleasure to thank the many people who made this thesis possible. I am grateful to my mother for her undying faith and love, and my sister for her insights and support throughout my life.

I consider myself very fortunate to have had the opportunity to work under Dr.Jacky Prucz. His encouragement and guidance is remarkable and I have learnt a lot under his tutelage. Working as his research assistant has been an enriching experience and has helped bring out some of my best work. I would also like to thank the professors on my committee, Dr.Samir Shoukry and Dr.Kenneth Means for their continued support throughout my research work.

Last, but not the least, I am grateful to all my friends for being the surrogate family during the years I stayed away from home and for their continued moral support thereafter. 


\section{Table of Contents}

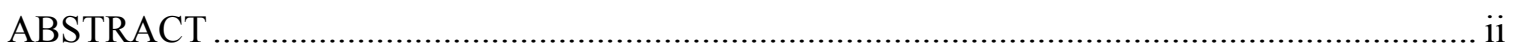

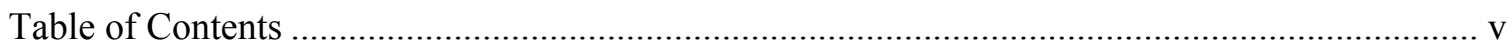

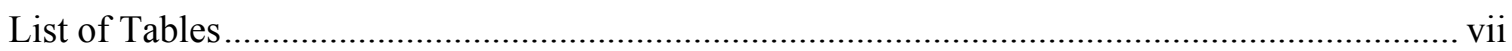

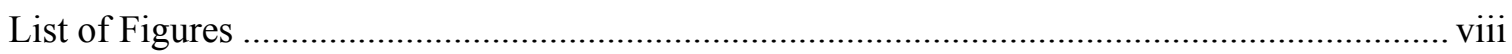

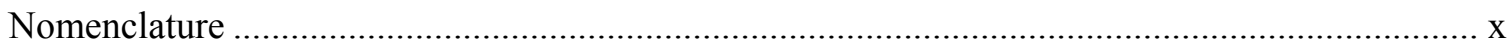

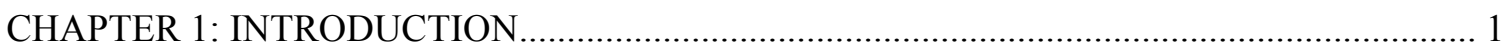

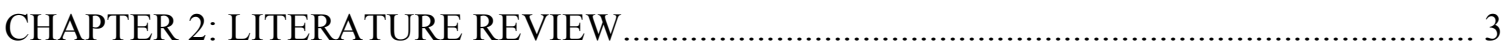

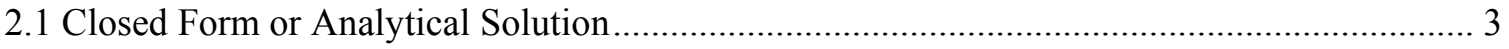

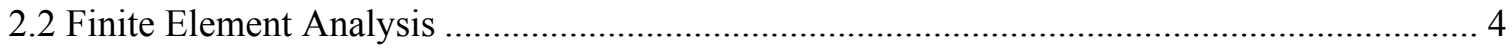

CHAPTER 3: CLOSED FORM MODEL OF THE DOUBLE LAP BONDED JOINT ............... 9

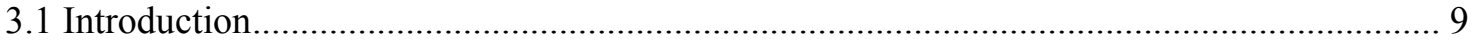

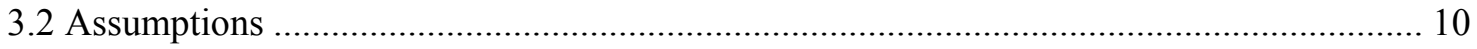

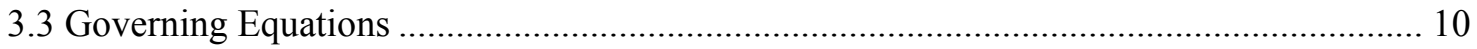

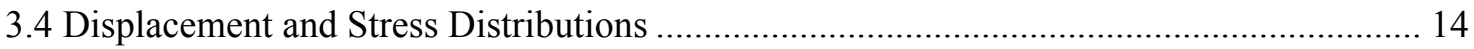

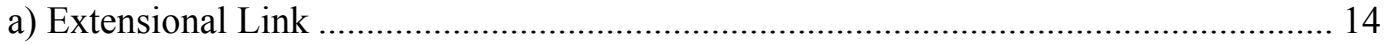

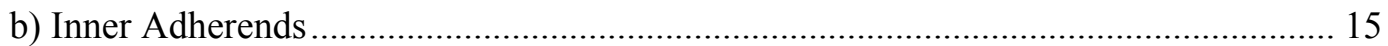

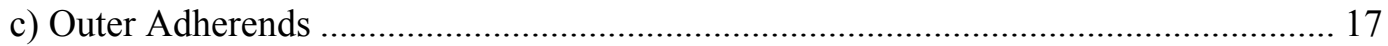

CHAPTER 4: FINITE ELEMENT MODEL OF THE DOUBLE LAP BONDED JOINT .......... 23

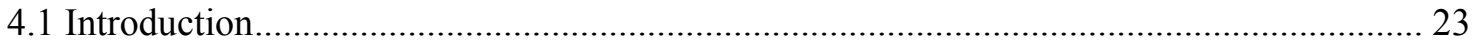

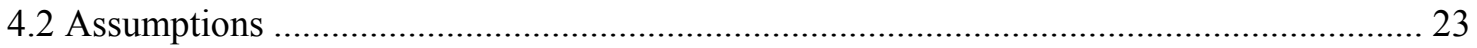

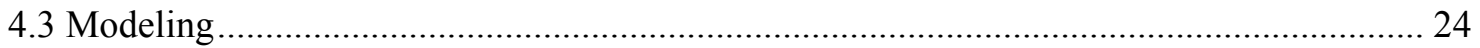

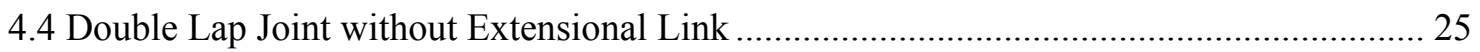

4.5 Double Lap Bonded Joint with Extensional Link .................................................................... 25

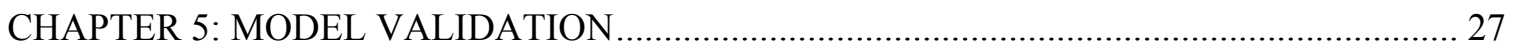

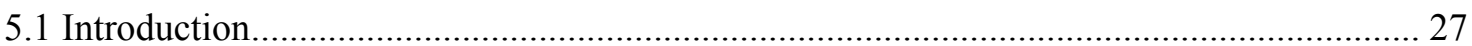

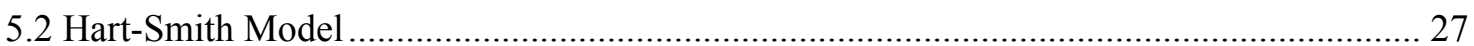

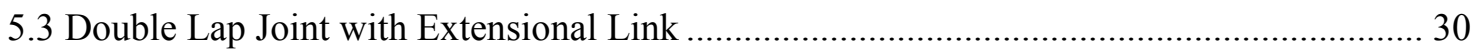

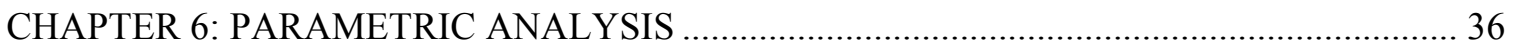

6.1 Parametric Studies Based on the Closed Form Model........................................................ 36

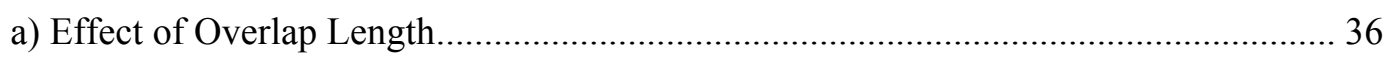

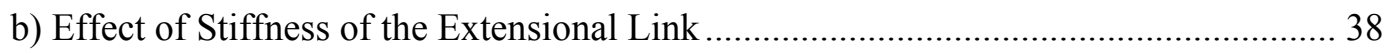

c) Effect of the Thickness of the Adhesive ……….......................................................... 39 


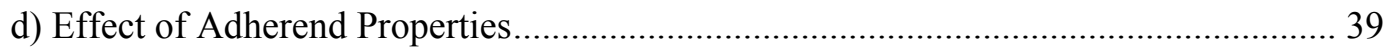

6.2 Parametric Studies Based on the Finite Element Model .................................................... 39

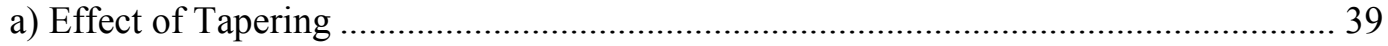

b) Comparisons between Single Lap versus Double Lap Configurations ......................... 40

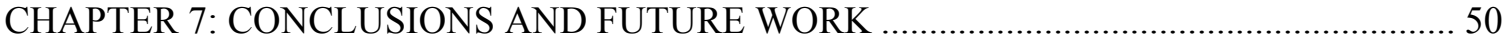

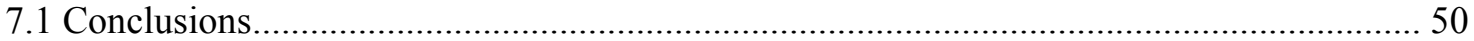

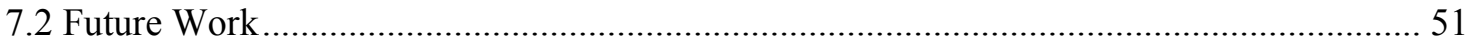

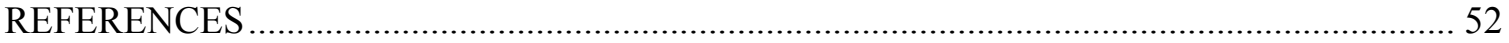

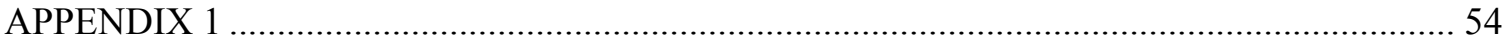




\section{List of Tables}

Table 5.1: Material Properties of the Components of the Double Lap Joint................................ 27

Table 5.2: Material Properties of the Components in the Double Lap Joint with the Extensional

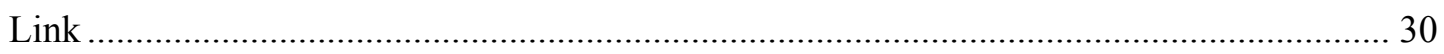

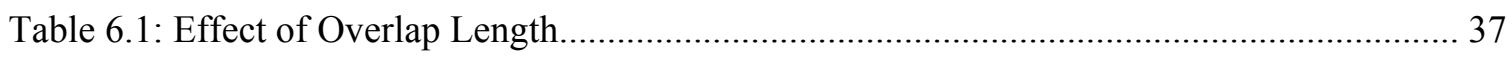

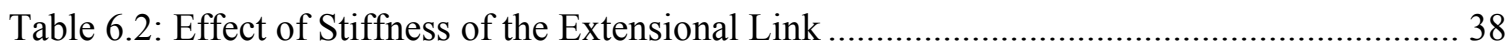

Table 6.3: Material Properties for Single Lap Bonded Joint ...................................................... 40

Table 6.4: Effect of Overlap Length on the Single and Double Lap Bonded Joints .................... 41 


\section{List of Figures}

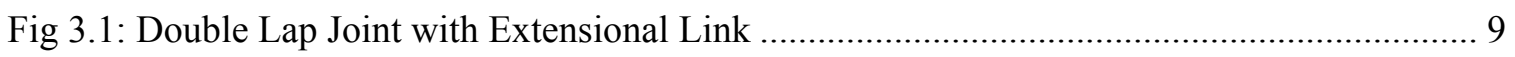

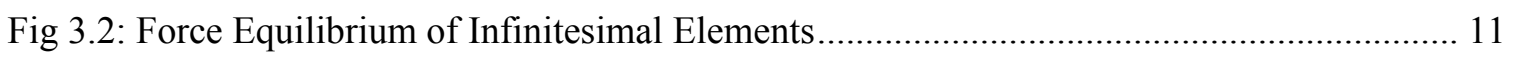

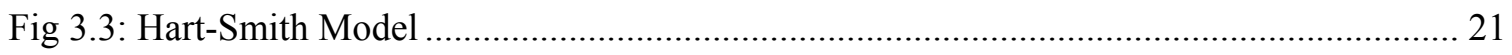

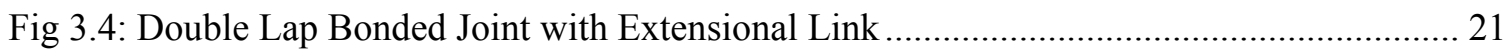

Fig 3.5: Shear Stress in the Adhesive along the Bond Length ................................................. 22

Fig 4.1: Finite Element Model of the Double Lap Bonded Joint ................................................. 23

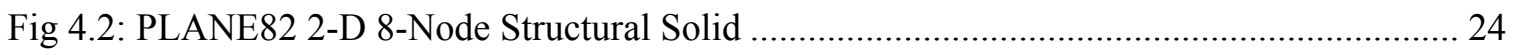

Fig 4.3: Finite Element model of the Hart-Smith Double Lap Bonded Joint............................... 26

Fig 4.4: Finite Element Model of the Double Lap Bonded Joint with Extensional Link.............. 26

Fig 5.1: Shear Stress in the Adhesive in the Hart-Smith Model.................................................. 28

Fig 5.2: Shear Stress in the Adhesive in the Double Lap Joint without Extensional Link........... 29

Fig 5.3: Axial Stresses in the Outer Adherend without the extensional link ................................ 32

Fig 5.4: Axial Displacements in Outer Adherend without the extensional link ........................... 32

Fig 5.5: Axial Stress in the Inner Adherend for the Double Lap Joint without the Extensional Link

Fig 5.6: Shear Stress in the Double Lap Joint with Extensional Link .......................................... 33

Fig 5.7: Axial Stress in the Outer Adherend for the Double Lap Joint with Extensional Link..... 34

Fig 5.8: Displacement of the Outer Adherend in the Double Lap Joint with Extensional Link.... 34

Fig 5.9: Axial Stress in the Inner Adherend with the Double Lap Joint with the Extensional Link

Fig 5.10: Displacement in the Inner Adherend in the Double Lap Joint with Extensional Link .. 35

Fig 6.1: Shear Stress in the Adhesive for Overlap Length $=50.8 \mathrm{~mm}$.

Fig 6.2: Variation of the Maximum Shear Stress in the Adhesive with the Tension Applied on the Joint $(\mathrm{L}=12.7 \mathrm{~mm})$

Fig 6.3: Variation of Maximum Shear Stress with the Overlap Length for Different Tensile

Forces.

Fig 6.4: Variation of Maximum Shear Stress with the Overlap Length for Different Stiffness

Values of the Extensional Link

Fig 6.5: Variation of Maximum Shear Stress with Stiffness of the Extensional Link for Different

Overlap Lengths. 44

Fig 6.6: Shear Stress of the Adhesive for Overlap Length L=50.8 for Different Thickness of

Adhesive. 
Fig 6.7: Shear Stress Distribution in the Adhesive for Different Adherend Materials.

Fig 6.8: Finite Element Model of Double Lap Joint with the Outer Adherends Tapered at an

Angle $45^{\circ}$ 45

Fig 6.9: Shear Stress Distribution in the Adhesive for the Adherend with Tapered Edge ............ 46

Fig 6.10: Spew Fillet Finite Element Model of the Double Lap Joint ........................................ 46

Fig 6.11: Distributions of Shear Stress in the Adhesive of a Double Lap Joint in the Presence and

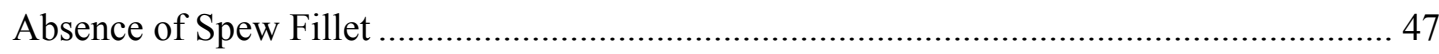

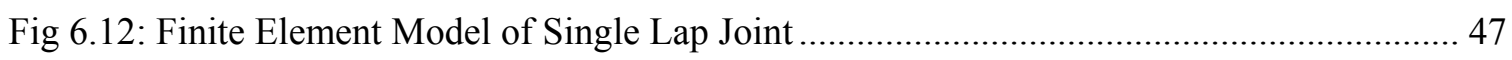

Fig 6.13: The Effect of Overlap Length on the Maximum Allowable Force for Single and Double

Lap Bonded Joint without Extensional Link ................................................................... 48

Fig 6.14: The Effect of Overlap Length on the Maximum Allowable Force for Single and Double

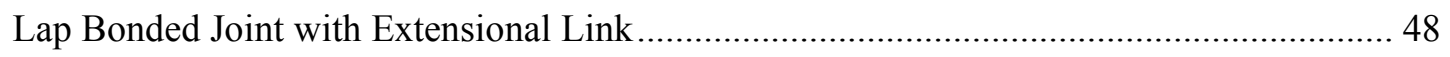

Fig 6.15: Effect of Extensional Link on Maximum Load that can be Transferred Through a Single

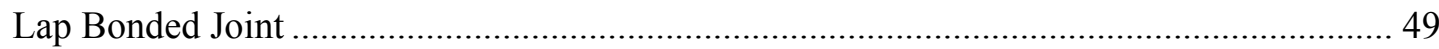




\section{Nomenclature}
$\mathrm{A}, \mathrm{B}=$ Shear stress coefficient
$\mathrm{G}=$ Shear modulus of the adhesive
$\mathrm{L} \quad=$ Overlap length
$1_{\mathrm{S}} \quad=$ Length of elastic link
$\mathrm{H} \quad=$ Non-dimensional parameter, defined in Eq 3.50
$\mathrm{K}=$ Non-dimensional parameter, defined in Eq 3.49
$\mathrm{P} \quad=$ Amplitude of external load
$\mathrm{t}_{\mathrm{i}}, \mathrm{t}_{\mathrm{o}} \quad=$ Thickness of inner and outer adherends respectively
$\mathrm{t}_{\mathrm{s}} \quad=$ Thickness of extensional link
$\mathrm{t}_{\mathrm{v}} \quad=$ Thickness of adhesive layer
$\mathrm{T}_{\mathrm{i}}(\mathrm{x}), \mathrm{T}_{\mathrm{o}}(\mathrm{x}) \quad=$ Internal force in inner and outer adherends respectively
$\mathrm{T}_{\mathrm{s}}(\mathrm{x}) \quad=$ Internal force in the extensional link
$\mathrm{u}_{\mathrm{og}}(\mathrm{x}) \quad=$ Axial displacement in gap portion of outer adherend
$\mathrm{u}_{\mathrm{i}}(\mathrm{x}), \mathrm{u}_{\mathrm{o}}(\mathrm{x}) \quad=$ Axial displacement in the inner and outer adherends respectively
$\mathrm{u}_{\mathrm{s}}(\mathrm{x}) \quad=$ Axial displacement in the extensional link
$\beta \quad=$ Non-dimensional parameter, defined in Eq 3.14
$\tau(\mathrm{x}) \quad=$ Shear stress amplitude in adhesive layer
$\tau_{, \mathrm{x}} \quad=$ Axial gradient of shear stress in the adhesive 


\section{CHAPTER 1: INTRODUCTION}

A number of individual components are connected to form an integral load transmission path in most of the structures. The so formed connections are termed as joints and they can be attained in many forms like bolting, welding, riveting or adhesive bonding. The potentially weakest points in the structures are the joints, so it becomes an important reason for designing the structural joints adequately so that the specific design requirements are met.

The ability to form light weight high strength and stiffness structures, ability to join thin sheet materials efficiently and the ability to join dissimilar metals makes the usage of adhesive bonding even more important. The overall structural integrity in the bonded joints is improved by avoiding many fasteners and the fastener holes. Also, the stress concentrations in the adherends are nullified unlike the mechanical fasteners, which produce points of stress concentrations.

Reliable stress analysis and strength evaluations are the most important criteria in the designing of an appropriate structural bonded joint. Due to their simplicity in construction single lap and double lap are the most commonly used specimen configurations for the shear test and also they represent a close resemblance to the geometry and service conditions for many structural adhesives. But double lap test has a low peel stress distribution compared to the single lap shear test. So the former can be represented as essentially peel-free joint [8].

Lot of research work is being done on the optimization of the bonded joints especially in the field of composite materials. Different factors and different criteria were taken into consideration in order to get lightweight and structurally strong joint. A variety of shapes for the adherends and a variety of material type for the adhesives are being considered to get an optimized joint. Even the co-cured composite joints are being studied and are being applied wherever they are more advantageous than the pure adhesive bonding. 
Many experiments are being performed by considering different geometries for the adherends and the adhesives. The tapered adherends are actually being studied which not only reduce the stress concentrations at the ends but also help in making a lighter joint. The results thus obtained are then validated using analytical solution or the finite element methods.

In the present research, a typical simple double lap joint is considered which is based on Hart-Smith model. An additional extensional link is included which connects the inner adherends and the equations are framed. The closed form model is validated using Finite Element Analysis with help of ANSYS software. A variety of parametric analysis is performed in order to observe the behavior of the double lap joint. 


\section{CHAPTER 2: LITERATURE REVIEW}

Adhesively bonded joints are substantially used in the manufacture of the fiber reinforced plastic adherends, aerospace vehicles, wooden articles and many light weight structural members [7]. Many mathematical models have been developed for different types of bonded joints but when there is a complexity in the problem then finite element modeling is an effective and an easy method to analyze the problem. From the literature it ahs been observed that both the analytical and the finite element methods have been used in the analysis of a few joints with typical configurations. In our present study also we have adapted both these methods for the analysis.

\subsection{Closed Form or Analytical Solution}

Hart-Smith's developed analytical solutions for different types of bonded joints like single-lap, double lap, and stepped joints etc which are used as a principle reference by lot of researchers. For the analytical solution for the double lap joints which concerns our interest he considered various types of adhesives like elastic, elasto-plastic, bi-elastic etc. A typical and simple model of a double lap joint was considered and detailed derivation for the shear stress in the adhesive was obtained as a function of a single variable which is the distance from the origin to the overlap [2].

A one-dimensional analytical model of a typical double lap joint considering visco-elastic behavior for the adhesives was developed by Prucz [1] and [3] in which the main emphasis was given on enhancing the inherent damping in the structures. The elastic link, which was used connecting the inner adherends, provided improved

minimum stiffness and structural redundancy at higher temperatures. Complex modulus was used to represent the shear modulus of the visco-elastic adhesive. The shear stress along the length of the adhesive was derived using which the strain energy was also calculated. The loss factor and the over all stiffness of the joint were calculated using the conventional formulae. It was concluded that even though the stiffer visco-elastic materials have low loss factors than the softer materials, a better damping stiffness 
tradeoffs is provided by them which is preferable for the applications in the passively damped joints.

M. Goland et al determined the stresses in the cemented lap joints in 1944 and these derivations are used as guidelines by many researchers for bonded lap joints. These equations were derived due to inventions of new methods to establish a stronger bond between plastic, wood or metal sheets. The loads at the edges of the joint and the stresses in the joint due to the applied loads were determined for two cases. In the first case the effect on the flexibility of the thin-cemented layer is neglected and in the second case the flexibility of the joint mainly depended on the cemented layer [18].

A quasi-2D closed form solution and a 3-D discrete analysis are discussed regarding the stress distributions in the adhesive and also the parent material and were tallied with experimental observations for a double lap joint. BONJO, which was developed by Lockheed-Martin and SAVE analysis programs are discussed briefly in this paper written by Rastogi and others [14]. Couples of specimens with different bond length, bond thickness and curing temperatures were experimented and the failure loads were obtained. At two different curing temperatures four specimens were tested and many important conclusions were made. Smaller bond length causes higher magnitude in stresses in the joint along the bond length and an increase in the bond thickness decreased the stresses especially at the edges. SAVE program predicted the transverse normal stresses better than the BONJO.

\subsection{Finite Element Analysis}

Many researchers have worked on bonded lap joints and finite element analysis is being very widely used to predict the structural behavior of the joints. An intensive study is being carried out to understand the behavior of the adhesive joints in terms of tapered adherends and also the crack propagation. Especially, in the field of composites the prediction of crack propagation becomes important because the failure of laminates depends on it. F. J. Guild et all [9] and [10] in their paper dealt with tapered adherends and adhesives and both experimentally and in FEA the results were validated. The 
adherends were considered to be isotropic and the adhesives were treated as a Drucker Prager model. Abaqus was used to analyze the joints. The major aspect was to find how the crack progresses so that it can be shown that bonded joints behave in a reliable and predictable way. It was understood from that the modification of the bonded joints was necessary for the growth of crack to be along the bond line. A continuous film or warm cloth had to be placed along the center of the bond line for it to be modified. After the analysis it was concluded that Kapton film or nylon mesh are the best inclusions.

A finite element model was developed to analyze the double lap shear wood connections in order to determine the effect of any desired material or any geometric parameter so that it can be expanded to account for other factors [8]. The results of the theoretical analysis indicate that the highest stresses develop at the ends of the overlap. The stress distribution is very non-uniform when the overlap joint is loaded in tension or compression. The model used linear elastic, orthotropic and homogenous material properties for the adherends. An 8 node quadrilateral elements are used for the representation of the wood adherends. Two orthogonal spring elements are used to represent the bond link where in one represents the shear stiffness and the other one represents the normal stiffness. The finite element model is mesh independent and also it does not rely on properties that are difficult to be determined. At the end of the analysis it is concluded that the normal and shear stresses are not uniform and the maximum values occurred at the ends of the overlapped regions. It was also concluded that with the increase in the overlap length, both the normal and shear distributions became more uniform and also the stress concentrations at the corners of the joint were reduced.

There are two types of parametric analysis, one is material parameters and the other is geometrical parameters. In the material parameters different types of adhesives and adherends are considered. The thickness of the adhesive, the overlap length and the thickness of the adherends are the factors, which are termed as geometric parameters. Shiuh-Chuan Her et al, from their analysis gave a slightly corrected analytical solution both for single and double lap joints [12]. It was observed that the stress from the finite element method is higher than the analytical solution. It was concluded that the increase 
in the adhesive thickness results in lower stress in the bonding region. When two different adherends are considered the maximum shear stress occurs at the free end of the adhesive region near to the stiffer adherend.

For the stress analysis of a composite to metal double lap joint a 3D full Lagrange 27 node finite element available in the ABAQUS package was used. Due to the symmetric conditions from the assumptions the analysis is reduced to $1 / 8^{\text {th }}$ of the original model. The main problem faced with this $3 \mathrm{D}$ model was that there were several lines where many zones of high stress gradients were possible. In general $3 \mathrm{D}$ analyses is an expensive process especially when the adhesives and the adherends are relatively thin and also the parametric refinement caused problems like zero or "negative element volume error". Thus the submodels analysis is used by Alexander Boganovich and Indrajith Kizhakkethara [4] which is available in the new version of ABAQUS. Finally a double lap bonded joint analysis was developed and the element was applied in both the global and local or submodel versions. The submodel approach provides with efficient tools for improving both the stress and deformations calculations at the corner.

Formation of composite structures by joining structural components has really become a very important part of the composite science and technology. Especially the adhesive bonded single lap joint is widely being used in the laminated composite structures [11]. Consistent and continuous efforts are being made to find new methods and also to improve the existing methods. The problem with the neat resin adhesives was that the joint strength is comparatively low and also the fabrication time is too long. Hence two types of prepeg composites were used to bond the single lap joints made of composite materials to increase the joint strength and to decrease the fabrication time. The specimens were tested as per the ASTM standards and also the results were validated using the finite element analysis. It was concluded that the prepeg bonded composite single lap joints comparatively have higher load carrying capacities than the joints prepared with neat resins. And also the residual load carrying capacity is also higher after 90 days $+\mathrm{UV}$ and sea water +UV conditioning. The better performance is due to the reduced peel stress and interfacial shear stress. 
Several researchers investigated the advantages of the co-cured joints over the adhesively bonded joining, one of them being the simultaneous achievement of curing and joining processes. Also they do not require any surface treatment of the composite laminate or any adhesive joining process because the excess resin accomplishes the cocured joining process. Surface roughness is a factor on which the static and the dynamic strengths of a lap joint depend. Even the bond length plays an important factor as the stress concentrations occur at the edges and corners of the lap joints. Also the stacking sequence is a parameter for the composite laminate a sit determines the strength of the joint. The tensile load bearing capacities of the co-cured double lap joints with respect to the above-mentioned parameters were tested experimentally, three-dimensional Tsai -Wu criterion was used to calculate the bond bearing capacities [5]. The results from the experiment were validated using finite element analysis. A stacked composite laminate with prepegs was basically pre-bonded to a steel adherend and tested. ABAQUS was used for the finite element and the resin thickness was not taken into consideration as it was very less when compared to the thickness of the adherends. Only a quarter model was analyzed due to the symmetric configuration. Finally it was concluded that the delamination occurred in the first ply due to cohesive failure, increment of the tensile load bearing capacity decreased after $0.7 \mu \mathrm{m}$ surface roughness and the stacking angle decreased the tensile load bearing capacity irrespective of the overlap length.

For the reduction of the failure modes associated with the delamination of the surface plies in the composite adherends, new joint designs were proposed by Yehia. A. Bahei. Ei. Din [13]. A better stress distribution in the adhesive is provided in these new designs. It was found that most of the load is transferred by in-plane shear and normal stress in these new joint configurations and this is done through the bonded inserts or interlocking interfaces that have the same thickness as the laminate adherends. With the similar dimensions of a conventional joint, new joints were designed with flat, pointed, diamond shaped inserts and also with an interlocking zigzag interface. From the finite element analysis it was concluded that, for both the conventional and the new designs the load transfer mechanism can improve the efficiency of the joint and this can be done by 
increasing the size of the adhesively bonded areas by making sure that the stresses in the adherends are uniform through the thickness of the laminate. 


\section{CHAPTER 3: CLOSED FORM MODEL OF THE DOUBLE LAP BONDED JOINT}

\subsection{Introduction}

A practical analytical model of a double lap joint is developed in this chapter. This model allows parametric studies to be conducted on the joint system. This is an onedimensional model where the shear stress is expressed as a function of only one variable, namely the length, The shear stress in the equation is expressed as a function of only one variable, which is the length and it is represented by ' $x$ '. From the distribution of the shear stress, other equations are derived to evaluate the axial stresses in the inner and the outer adherends are also derived. From the axial stresses the deformations in the inner and the outer adherends are also calculated. All these equations are used to plot distributions of various parameters along the overlap length and their predictions are compared with the results from finite element analysis in the next chapter.

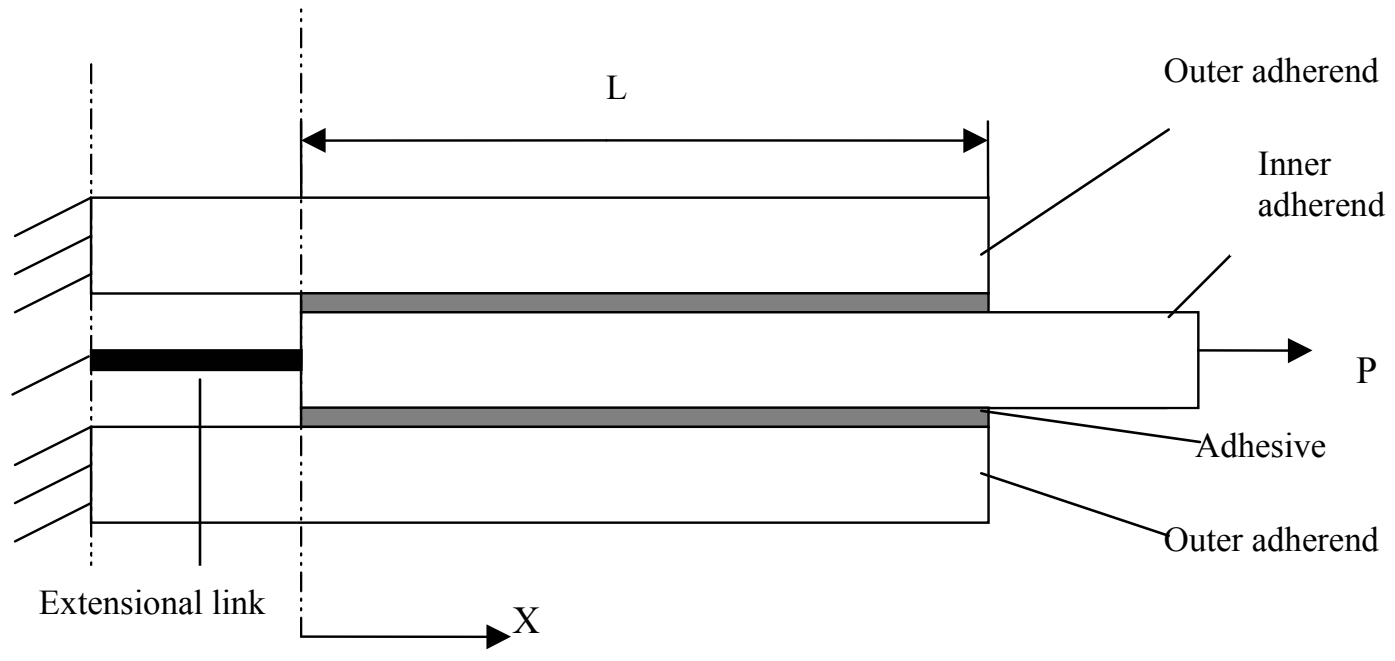

Fig 3.1: Double Lap Joint with Extensional Link

Figure 3.1 represents the double lap joint with the extensional link that is expected to reduce the maximum shear stress in the adhesive, as well as the axial displacement of the linear adherend. As indicated in the figure, the joint has two outer adherends and one inner adherend, adhesive bonding between the inner and the outer adherends and an 
extensional link. Due to the symmetry only half of the model is considered and analyzed to obtain the required equations.

\subsection{Assumptions}

The analytical model is based upon a symmetrical double lap joint configuration as shown in the figure. Simplicity and its suitability in the space structures wherein the main loading direction of the members is axial are the reasons behind the selection of this configuration.

The inner and the outer adherends are elastic in nature with isotropic properties.

The adhesive is an isotropic material and is assumed to behave like a perfectly elastic material.

An elastic link is included in this model, which is used as a restoring elastic rod along the axial direction.

The only external load acting on the double lap joint is the fluctuating axial force applied on one of the member (inner adherend), which is transferred through the joint to the other member.

The present analysis can be described by a single co-ordinate as it is confined to a uniaxial response.

Inertia and frequency effects are neglected and the attention is only restricted to a quasistatic analysis of the joint behavior under the fluctuating axial load.

\subsection{Governing Equations}

To formulate the equations for the stresses and the displacements in the various elements of the double lap joint it is important that the free body diagrams are considered for the inner and the outer adherends and also the adhesive. Fig 3.2 represents the free body diagram of infinitesimal elements

$$
\begin{aligned}
& T_{i, x}-2 \tau(x)=0 \\
& T_{o, x}+\tau(x)=0
\end{aligned}
$$



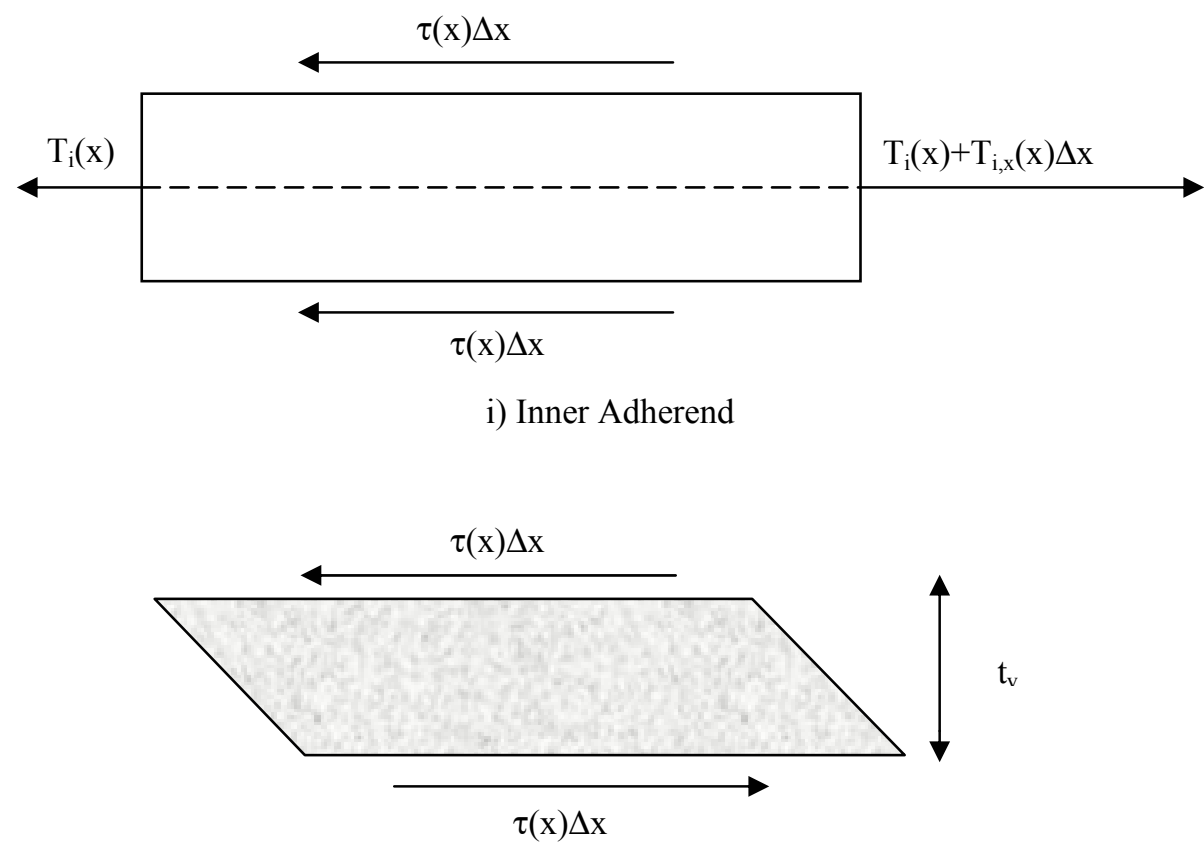

ii) Adhesive Layer

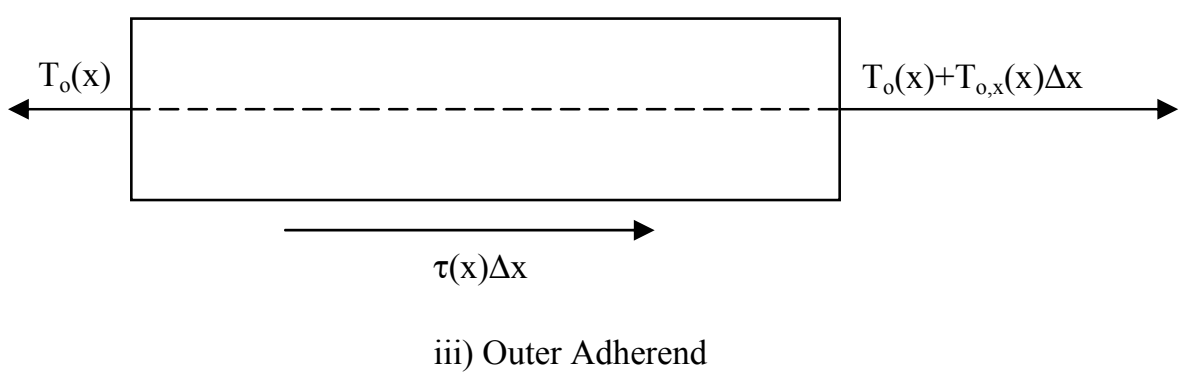

Fig 3.2: Force Equilibrium of Infinitesimal Elements

The extensional deformations in the adherends are perfectly elastic, so the relations for the inner and outer adherends respectively can be expressed as follows:

$\mathrm{u}_{\mathrm{i}, \mathrm{x}}=\mathrm{T}_{\mathrm{i}}(\mathrm{x}) /\left(\mathrm{E}_{\mathrm{i}} \mathrm{t}_{\mathrm{i}}\right)$

$\mathrm{u}_{\mathrm{o}, \mathrm{x}}=\mathrm{T}_{\mathrm{o}}(\mathrm{x}) /\left(\mathrm{E}_{\mathrm{o}} \mathrm{t}_{\mathrm{o}}\right)$

By considering the geometry of the deformations as in the figure a kinematic relationship between the shear strain and the axial displacements in the adhesives can be established.

$\gamma(x)=\left(u_{i}(x)-u_{o}(x)\right) / t_{v}$ 
Considering the relation between the shear stress and the shear strain in the adhesives we have

$\tau(\mathrm{x})=\mathrm{G} \gamma(\mathrm{x})$

Let

$\Delta(\mathrm{x})=\mathrm{u}_{\mathrm{i}}(\mathrm{x})-\mathrm{u}_{\mathrm{o}}(\mathrm{x})$

So we have

$\tau(\mathrm{x})=\mathrm{G}\left(\Delta(\mathrm{x}) / \mathrm{t}_{\mathrm{v}}\right)$

By differentiating Equations (3.3) and (3.4) and by using the expressions from (3.1) and (3.2) we have

$\mathrm{u}_{\mathrm{i}, \mathrm{xx}}=\left(2 / \mathrm{E}_{\mathrm{i}} \mathrm{t}_{\mathrm{i}}\right) \tau(\mathrm{x})$

$\mathrm{u}_{\mathrm{o}, \mathrm{xx}}=-\left(1 / \mathrm{E}_{\mathrm{o}} \mathrm{t}_{\mathrm{o}}\right) \tau(\mathrm{x})$

Subtracting the above two equations from each other and substituting the Equations (3.7) and (3.8) we have

$\frac{t_{v}}{G} \tau_{, x x}=\left(\frac{1}{E_{o} t_{o}}+\frac{2}{E_{i} t_{i}}\right) \tau(x)$

The above equation is the basic governing equation of the model and it can be expressed both in terms of stresses and strains respectively:

$$
\begin{aligned}
& \tau_{, x x}-\frac{\beta^{2}}{l^{2}} \tau(x)=0 \\
& \Delta_{, x x}-\frac{\beta^{2}}{l^{2}} \Delta(x)=0
\end{aligned}
$$

The constant $\beta$ is defined as follows:

$$
\beta^{2}=\frac{G}{E_{i}}\left(\frac{E_{i} t_{i}}{E_{o} t_{o}}+2\right) \frac{l^{2}}{t_{v} t_{i}}
$$


The differential Equation (3.11) is similar to the equation in the Hart-Smith's model but the constant used here $\beta$ is a non-dimensional formula whereas in Hart-Smith's model the constant used is $\lambda$ and it has dimension 1-1.

The general solution of the differential equation is

$$
\tau(x)=A \sinh \left(\frac{\beta x}{l}\right)+B \cosh \left(\frac{\beta x}{l}\right)
$$

The constants A and B can be determined using the boundary conditions imposed on the shear stress gradient at the ends of the overlap of the joint. The requirement that the load transfer from the inner to the outer adherends is carried out through the adhesive shear deformation such that the gross axial equilibrium of the joint is always maintained is reflected by these boundary conditions. The shear gradient expression is derived from the Equations (3.7) and (3.8).

$$
\tau_{, x}=\frac{G}{t_{v}}\left(u_{i, x}-u_{o, x}\right)
$$

From Equations (3.3), (3.4), (3.15), (3.16) the following equation is obtained:

$$
A \frac{\beta}{l} \cosh \left(\frac{\beta x}{l}\right)+B \frac{\beta}{l} \sinh \left(\frac{\beta x}{l}\right)=\frac{G}{t_{v} b}\left(\frac{T_{i}(x)}{E_{i} t_{i}}-\frac{T_{o}(x)}{E_{o} t_{o}}\right)
$$

By applying the boundary conditions at $\mathrm{x}=0$ and $\mathrm{x}=1$ in the above equation, the values of the constants A and $\mathrm{B}$ can be determined.

When " $\mathrm{x}=0$ " condition is substituted in Equation (3.17) the expression for the constant $\mathrm{A}$ can be written as

$$
A=\frac{l}{\beta t_{v}} G\left(\frac{T i(0)}{E_{i} t_{i}}-\frac{T_{o}(0)}{E_{o} t_{o}}\right)
$$


By applying equilibrium conditions at the boundary $\mathrm{x}=1$ we have

$$
T_{i}(l)=P
$$

$T_{o}(l)=0$

These conditions should satisfy Equation (3.17), so we have

$A \frac{\beta}{l} \cosh (\beta)+B \frac{\beta}{l} \sinh (\beta)=\frac{G}{t_{v} E_{i} t_{i}} P$

By substituting the value of constant A from (3.18) in (3.21) the constant B is obtained

$$
B=\frac{l}{\beta t_{v} \sinh (\beta)} G\left[\frac{P-T_{i} \cosh (\beta)}{E_{i} t_{i}}+\frac{T_{o}(0) \cosh (\beta)}{E_{o} t_{o}}\right]
$$

From the Equations (3.18) and (3.22) we can notice that the constants A and B have the dimensions of stress.

In the Hart-Smith model as the direct elastic link is absent, the inner adherend force boundary must vanish. Therefore we will have $\operatorname{Ti}(0)=0$ and only $\operatorname{To}(0)$ has to be evaluated. This can be done by using the overall axial equilibrium condition $T_{i}(0)+2 T_{o}(0)=P$

But this equation alone is not enough for the present model as there is a direct elastic link and therefore $\operatorname{Ti}(0) \neq 0$.

\subsection{Displacement and Stress Distributions}

\section{a) Extensional Link}

The basic equations of the previous sections with appropriate boundary conditions are utilized to derive the complete displacement and stress fields. The internal strip that 
provides an elastic link between the inner adherends of the joint is included in the present model. The symbols related to this element are all represented with a subscript "s". The internal force is constant along its length, as it is not embedded in the adhesive. Thus we can obtain the link deformation as follows:

$$
u_{s, x}=\frac{T_{i}(0)}{E_{s} t_{s}}
$$

So the displacement field for the extensional link is

$$
u_{s}(x)=\frac{T_{i}(0)}{E_{s} t_{s}} x+C_{s}
$$

Cs is integration constant and can be determined by using the boundary condition across the line of symmetry of the joint:

$$
u_{s}(-l)=0
$$

So substituting this condition the value of $\mathrm{C}_{\mathrm{s}}$ can be obtained as:

$$
C_{s}=\frac{T_{i}(0) l_{s}}{E_{s} t_{s}}
$$

\section{b) Inner Adherends}

The displacement at the interface between the extensional link and the inner adherend can be expressed as

$u_{i}(0)=\frac{T_{i}(0)}{E_{s} t_{s}} l_{s}$

The axial force distribution $\mathrm{T}_{\mathrm{i}}(\mathrm{x})$ can be obtained from the expression

$T_{i}(x)=2 \int \tau(x) d x+C_{i t}$ 
By substituting the shear stress from the Equations (3.15) we have

$T_{i}(x)=\frac{2 l}{\beta}\left(A \cosh \left(\frac{\beta x}{l}\right)+B \sinh \left(\frac{\beta x}{l}\right)\right)+C_{i t}$

From the boundary condition (3.19) the constant $C_{i t}$ can be determined as

$$
C_{i t}=P-\frac{2 l}{\beta}(A \cosh (\beta)+B \sinh (\beta))
$$

The displacement distribution along the length of the adherend can be determined by the following equation:

$u_{i}(x)=\frac{1}{E_{i} t_{i}} \int T_{i}(x) d x+C_{i u}$

By substituting the Equation (3.30) in the above equation:

$$
u_{i}(x)=\frac{2}{t_{i}}\left(\frac{l}{\beta}\right)^{2}\left[\frac{A}{E_{i}} \sinh \left(\frac{\beta x}{l}\right)+\frac{B}{E_{i}} \cosh \left(\frac{\beta x}{l}\right)\right]+\frac{C_{i t}}{E_{i} t_{i}} x+C_{i u}
$$

As neither of the inner adherends is constrained, its displacement field consists of rigid-body motion represented by the constant Ciu. By substituting $\mathrm{x}=0$ in Equation (3.33) it becomes:

$u_{i}(0)=\frac{2}{t_{i}}\left(\frac{l}{\beta}\right)^{2} \frac{B}{E_{i}}+C_{i u}$

The value of $u_{i}(0)$ from the Equation (3.28) can be substituted to evaluate $C_{i u}$ :

$$
C_{i u}=\frac{T_{i}(0)}{E_{s} t_{s}} l_{s}-\frac{2}{t_{i}}\left(\frac{l}{\beta}\right)^{2} \frac{B}{E_{i}}
$$




\section{c) Outer Adherends}

The outer adherend force distribution can be determined from the Equation (3.2) by substituting the equation for the shear stress in the adhesive from Equation (3.15) and then followed by integration, which gives the following equation:

$$
T_{o}(x)=-\frac{l}{\beta}\left(A \cosh \left(\frac{\beta x}{l}\right)+B \sinh \left(\frac{\beta x}{l}\right)\right)+C_{o t}
$$

But $\mathrm{T}_{\mathrm{o}}(1)=0$, so by substituting this in the equation above the value of the integration constant $\mathrm{C}_{\mathrm{ot}}$ can be determined as follows:

$$
C_{o t}=\frac{l}{\beta}[A \cosh (\beta)+B \sinh (\beta)]
$$

Considering the integration of the Equation (3.4):

$u_{o, x}=\frac{1}{E_{o} t_{o}} \int T_{o}(x) d x+C_{o u}$

By substituting Equation (3.36) in (3.38)

$u_{o}(x)=-\frac{1}{E_{o} t_{o}}\left(\frac{l}{\beta}\right)^{2}\left[A \sinh \left(\frac{\beta x}{l}\right)+B \cosh \left(\frac{\beta x}{l}\right)\right]+\frac{C_{o t}}{E_{o} t_{o}}+C_{o u}$

Evaluation of the Equation (3.39) at $\mathrm{x}=0$ yields:

$u_{o}(0)=-\frac{1}{t_{o}}\left(\frac{l}{\beta}\right)^{2} \frac{B}{E_{o}}+C_{o u}$

$\mathrm{C}_{\text {ou }}$ can be determined from the boundary conditions imposed on the outer adherends displacements at the line of symmetry of the joint.

$u_{g}\left(-l_{s}\right)=0$ 
$\mathrm{u}_{\mathrm{g}}$ represents the gap portion from the line of symmetry to the origin $\mathrm{x}=0$ i.e. it is the portion where there is no adhesive. The governing differential equation of the gap portion is:

$u_{g}=\frac{T_{o}(0)}{E_{o} t_{o}}$

Thus the displacement distribution can be written as:

$u_{\text {og }}(x)=\frac{T o(0)}{E_{o} t_{o}}(x+l s)$

At the interface between the gap and the load transfer portions of the outer adherends it becomes necessary that

$u_{o}(0)=u_{o g}(0)$

For the displacement compatibility, the above condition has to be satisfied.

By substituting Equations (3.40) and (3.43) into this condition gives the following expression for the integration constant $\mathrm{C}_{\mathrm{ou}}$ :

$C_{\text {ou }}=\frac{1}{t_{o}}\left(\frac{l}{\beta}\right)^{2} \frac{B}{E_{o}}+\frac{T_{o}(0)}{E_{o} t_{o}} l_{s}$

From the Equations (3.40) and (3.45) the expression for the displacement for the outer adherend at $\mathrm{x}=0$ can be written:

$u_{o}(0)=\frac{T_{o}(0)}{E_{o} t_{o}} l_{s}$

The axial displacements in the inner and outer adherends along the overlap portion are related through the deformation compatibility requirement of the adhesive layers. Thus by evaluating the Equation (3.6) at $\mathrm{x}=0$ the following expression is obtained: 
$\tau(0)=\frac{G}{t_{v}}\left[u_{i}(0)-u_{o}(0)\right]$

Among the four unknown parameters $A, B, T_{i}(0)$ and $T_{0}(0)$, the fourth relationship can be established by substituting the Equations (3.15), (3.35) and (3.46) into the Equation (3.47):

$B=G \frac{l_{s}}{t_{v}}\left[\frac{T_{i}(0)}{E_{s} t_{s}}-\frac{T_{o}(0)}{E_{o} t_{o}}\right]$

Let

$K=1-\frac{1-\cosh (\beta)}{\beta \sinh (\beta)} \frac{l E_{s} t_{s}}{E_{i} t_{i}}$

$H=2+\frac{E_{s} t_{s}}{E_{o} t_{o}}+\frac{\cosh (\beta)}{\beta \sinh (\beta)} \frac{l E_{s} t_{s}}{l_{s} E_{i} t_{i}}\left(2+\frac{E_{i} t_{i}}{E_{o} t_{o}}\right)$

The four unknown parameters $\mathrm{A}, \mathrm{B}, \mathrm{T}_{\mathrm{i}}(0)$ and $\mathrm{T}_{\mathrm{o}}(0)$ can be determined by solving the Equations (3.18), (3.22), (3.23) and (3.48) as following:

$$
\begin{aligned}
& A=\frac{l}{\beta t_{v}} \frac{G}{E_{i}} \frac{P}{t_{i}}\left[1-\frac{K}{H}\left(2+\frac{E_{i} t_{i}}{E_{o} t_{o}}\right)\right] \\
& B=\frac{l_{s} G P}{t_{v} E_{s} t_{s}}\left[1-\frac{K}{H}\left(2+\frac{E_{s} t_{s}}{E_{o} t_{o}}\right)\right] \\
& T i(0)=P\left(1-2 \frac{K}{H}\right) \\
& T_{o}(0)=P \frac{K}{H}
\end{aligned}
$$

In the absence of the extensional link i.e. as $\mathrm{E}_{\mathrm{s}} \mathrm{t}_{\mathrm{s}} \rightarrow 0, \mathrm{~T}_{\mathrm{i}}(0)$ also tends to zero and the values of $\mathrm{K}$ and $\mathrm{H}$ will become 1 and 2 respectively. 
In order to derive the equations for the double lap joint without the extensional link the material properties and the dimensions of the extensional link are substituted as zero.

Thus, the shear stress in the adhesive, the axial stresses in the inner and outer adherends and the displacement in the outer adherend can be found easily by substituting the stiffness and the dimensions of the extensional link as zero and by applying the required boundary conditions. But as the inner adherend is not constrained at either ends it becomes difficult to find the integral constant $\mathrm{C}_{\mathrm{iu}}$.

All the equations thus derived are then written as a program using MAPLE software in order to see the shear distribution in the adhesive along the bond length, the axial stresses and axial displacements in the inner and the outer adherends along the bond length. Figure (3.5) is the profile of the shear stress in the adhesive along the bond length. The material properties substituted are taken from reference [1]. The shear stress decreases initially and then increases and is maximum at the free end as the force is applied at that end. 


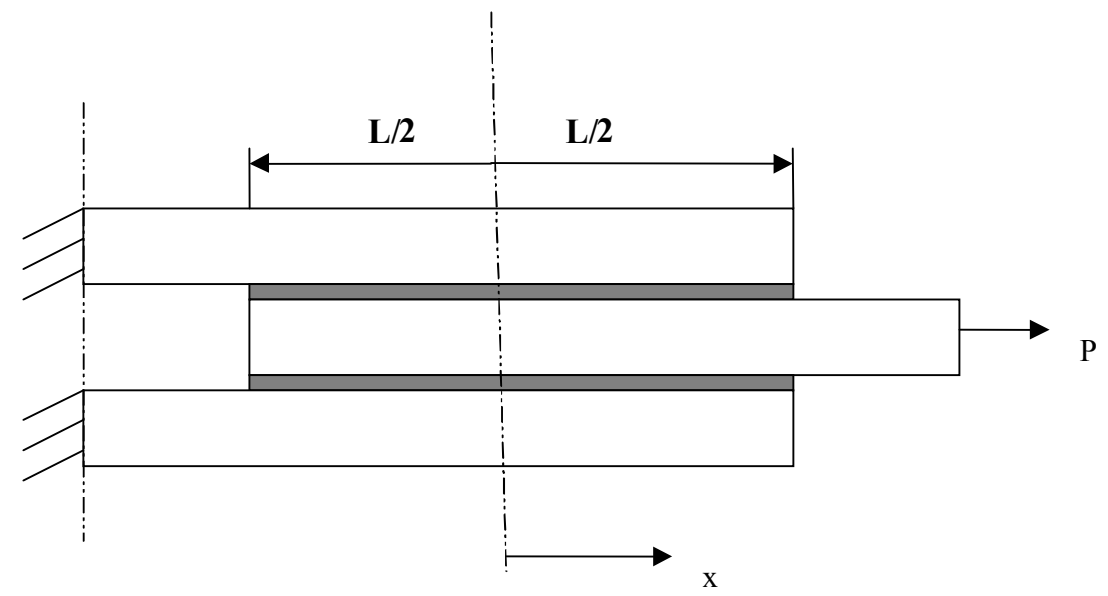

Fig 3.3: Hart-Smith Model

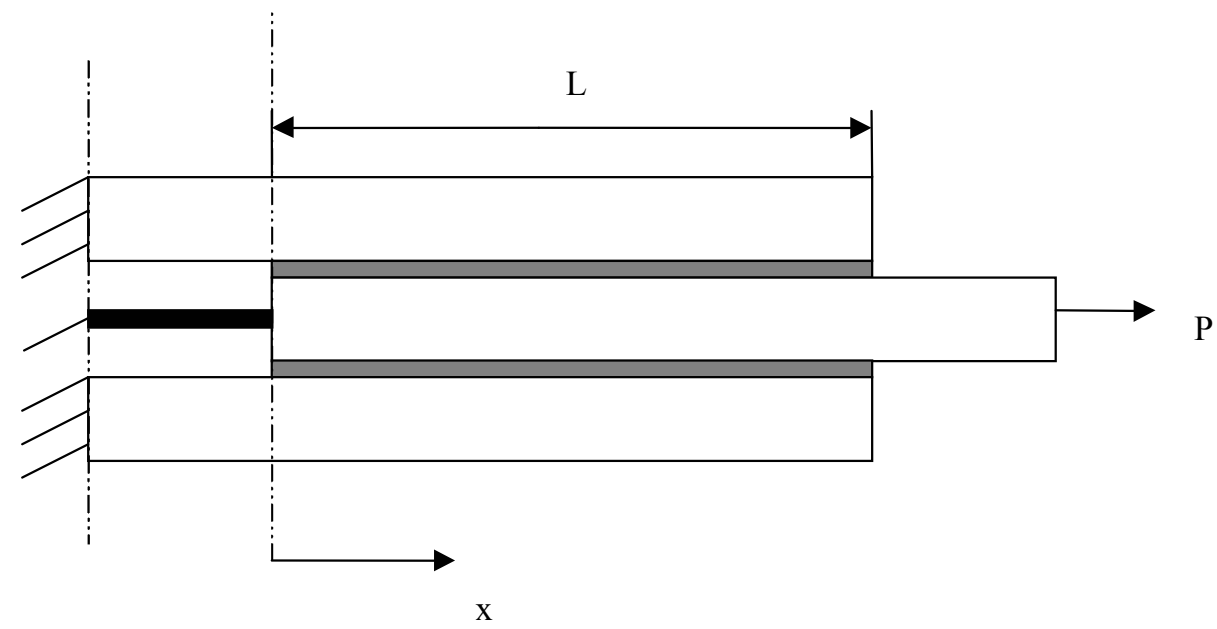

Fig 3.4: Double Lap Bonded Joint with Extensional Link 


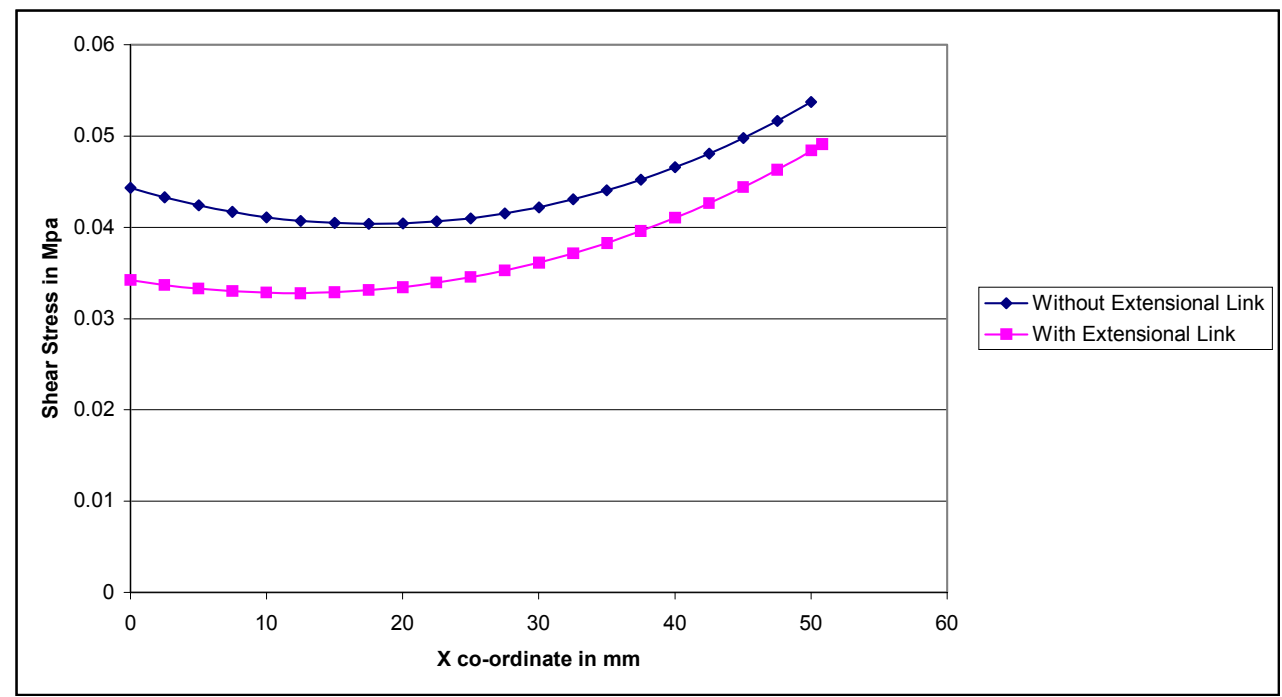

Fig 3.5: Shear Stress in the Adhesive along the Bond Length 


\section{CHAPTER 4: FINITE ELEMENT MODEL OF THE DOUBLE LAP BONDED JOINT}

\subsection{Introduction}

"The main purpose of a finite element analysis is to recreate mathematically the behavior of an actual engineering system." A 2D finite element model of a double lap joint is developed in this chapter. The model is the validation of the closed form model used in this thesis. The model allows a parametric analysis to be done in order to optimize the joint.

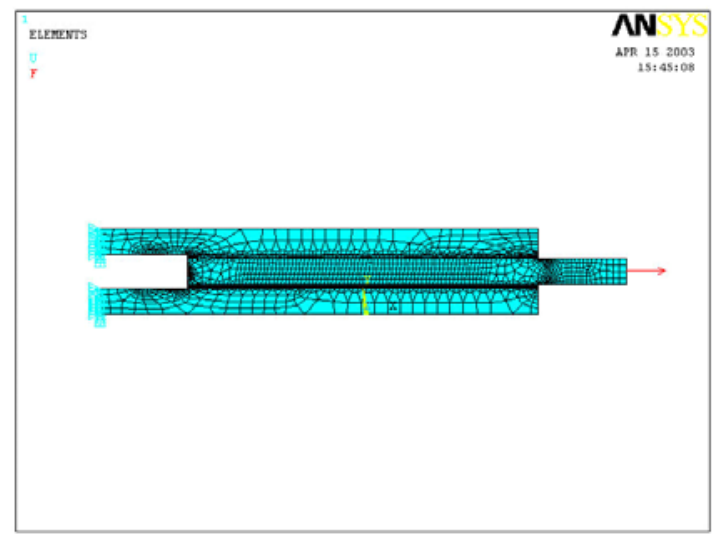

Fig 4.1: Finite Element Model of the Double Lap Bonded Joint

Figure (4.1) represents the finite element model of the double lap joint without an extensional link. One end of both the outer adherends is constrained in all degrees of freedom and at the other end a force $\mathrm{P}$ is applied on the inner adherend.

\subsection{Assumptions}

The finite element model is a symmetric, simple and widely used double lap configuration. The only external load acting on the joint is the axial force applied on one of the members. In this joint configuration the axial load applied is transferred through the joint from one member to another by the shear stress in the adhesive layers. The plane 
stress or plane strain conditions are applied on the model. The adherends are the adhesives are considered to be elastic in nature.

\subsection{Modeling}

Ansys 6.1 is used to model the double lap joint. If the thickness of the adhesive is small when compared to the thickness of the adherend then in the finite element model the adhesive thickness can be ignored, so the two adherends are bonded as perfectly bonded without the adhesive included. But in our present model both the adhesive and the adherends are modeled and the bonding between the adhesive and the adherend are considered to be perfect.

PLANE82 is a 2-D 8-noded element and it is a higher order version of the twodimensional, four-node element PLANE42. PLANE82 is more accurate is results for mixed (quadrilateral-triangular) automatic meshes. Without much loss of accuracy PLANE82 element can tolerate irregular shapes. The Figure 4.2 is the representation of PLANE82 element [19].

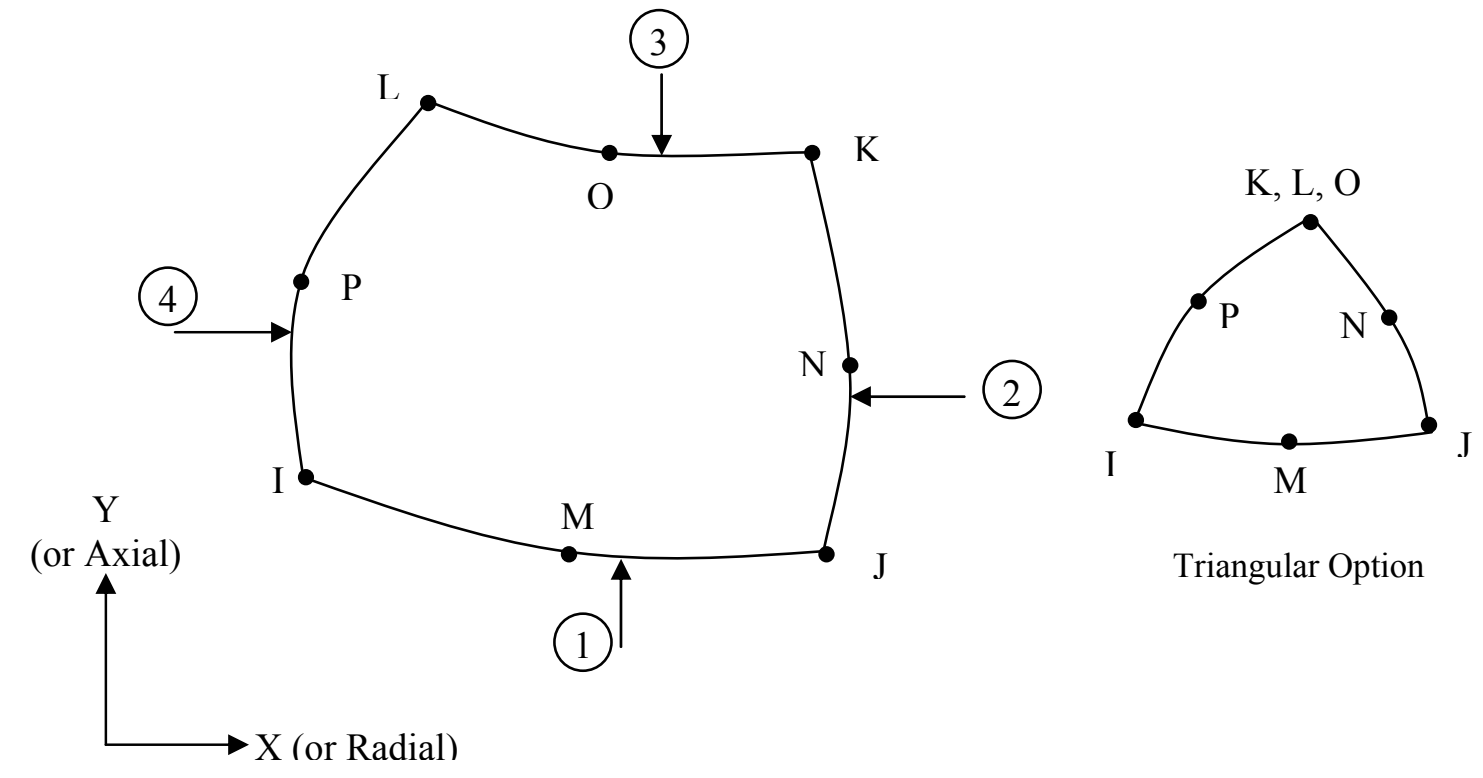

Fig 4.2: PLANE82 2-D 8-Node Structural Solid

There are 8 nodes in PLANE82 element and each node has two degrees of freedom which are translations in $\mathrm{x}$ and $\mathrm{y}$ directions. The mixed automatic meshes are 
advantageous especially near the bond between the adhesive and the adherends where the stress concentrations exist.

\subsection{Double Lap Joint without Extensional Link}

Initially the Hart-Smith's model is created and analyzed. The difference between the bonded double lap joint by Hart-Smith and Prucz is there is an extensional link in the latter model and also the origin is different in both the models. Both the cases are considered for the double lap bonded joint developed by Prucz, with and without the extensional link.

In the Hart-Smith's model and also in the present model two-dimensional system is considered. At the center of the bond length the origin is considered. The element type used is PLANE82 for both the adherends and also the adhesive. The mesh is refined for both adherends and adhesive at the bond. The outer adherends are constrained in all degrees of freedom on one end. A concentrated force is applied on the inner adherend at the free end of the joint. Figure 4.3 represents the finite element model of the double lap bonded joint developed by Hart-Smith. The boundary conditions are also represented in the figure. Static analysis is performed on the finite element model. The required results can be observed using the general post processor in the menu.

The double lap bonded joint developed by Prucz also is similar to Hart-Smith model when it is without extensional link, but the origin in this model is at the beginning of the bond length. The modeling of the adherends and adhesive is similar to the HartSmith model.

\subsection{Double Lap Bonded Joint with Extensional Link}

The element type used for both the adhesives and the adherends is PLANE82. For the extensional link either a beam element or 8-noded quadrilateral element can be used. In the present model PLANE82 element is used for the extensional link. The symmetry is taken into consideration and only half of the double lap joint is modeled. At one end the symmetry conditions are applied and at the other end a small axial force is applied. A 
concentrated force is applied on the inner adherend at the free end. Figure 4.4 represents the double lap joint with the extensional link. The boundary conditions are also represented in the figure. Static analysis is performed on this finite element model. The required results can be observed using the general post processor.

For both the models in Section 4.4 and 4.5 the dimensions and the materials properties used for the adherends, adhesive and the extensional link used are from the reference [1]. The material properties and the dimensions can be changed as required.

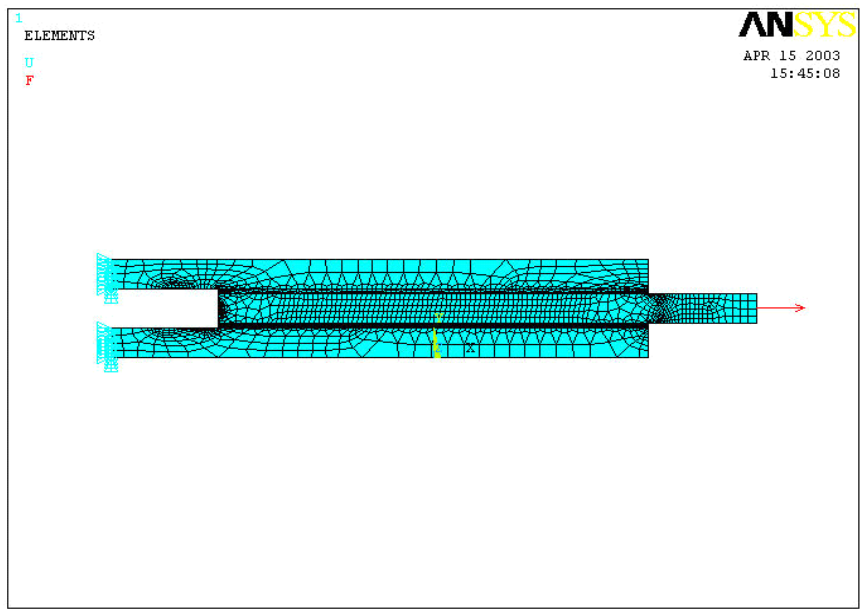

Fig 4.3: Finite Element model of the Hart-Smith Double Lap Bonded Joint

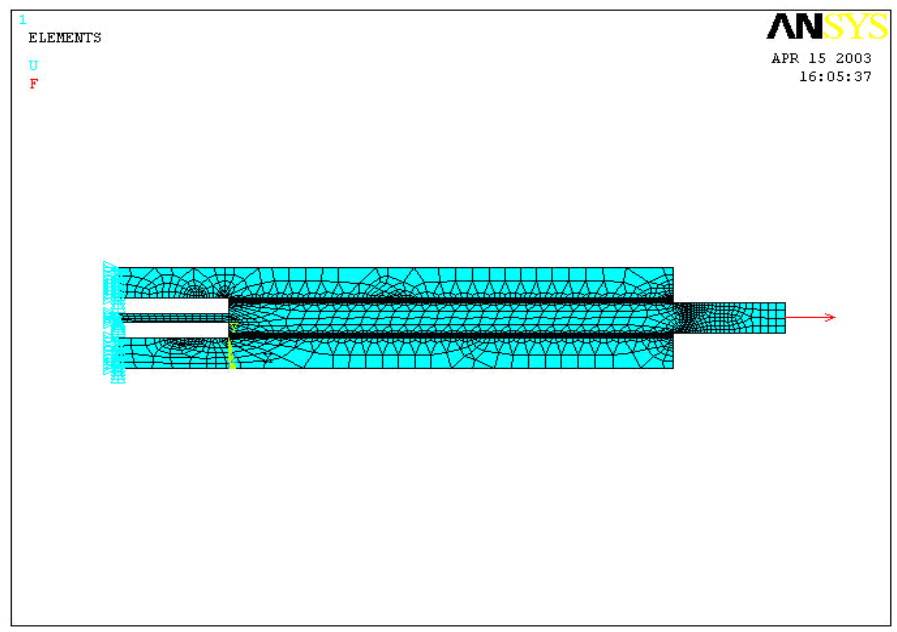

Fig 4.4: Finite Element Model of the Double Lap Bonded Joint with Extensional Link 


\section{CHAPTER 5: MODEL VALIDATION}

\subsection{Introduction}

In the Chapter 3 the equations for the closed form model for the double lap bonded joint are derived and in Chapter 4 the finite element model of the bonded lap bonded joint is created and analyzed. In this chapter the finite element model is validated using the equations from the closed form. The double lap bonded joint without and with extensional link are considered in this chapter.

\subsection{Hart-Smith Model}

The following properties were used in the finite element model in order to compare and validate it with closed-form model.

Table 5.1: Material Properties of the Components of the Double Lap Joint

\begin{tabular}{|c|c|c|}
\hline Components & Young's modulus & Poisson's ratio \\
\hline Adherend & $107593 \mathrm{Mpa}$ & 0.3 \\
\hline Adhesive & $107.588 \mathrm{Mpa}$ & 0.3 \\
\hline
\end{tabular}

The shear stress along the thickness is assumed to be uniform, and hence the shear stress along the length of the adhesive is considered as one of the parameters to validate the finite element analysis. The shear stress in the adhesive is given by the formula

$$
\tau(x)=A \sinh (\lambda x)+B \cosh (\lambda x)
$$

The constant $\lambda=\beta / 1$ as mentioned in the previous chapter. Also the detailed derivations of the constants $\mathrm{A}$ and $\mathrm{B}$ are also given in the previous chapter. Maple software is used to generate the graphs from the closed form equations. The shear stress of the adhesive is plotted along the length i.e. the x co-ordinate for both the finite element and the closed form solution. Fig 5.1 is the plot of the shear stress in the adhesive and from that it can be concluded that the finite element results match with the closed form and that the validation is successfully done. But at the corners the finite element model shows high stresses, which is due to the effect of the mesh. 


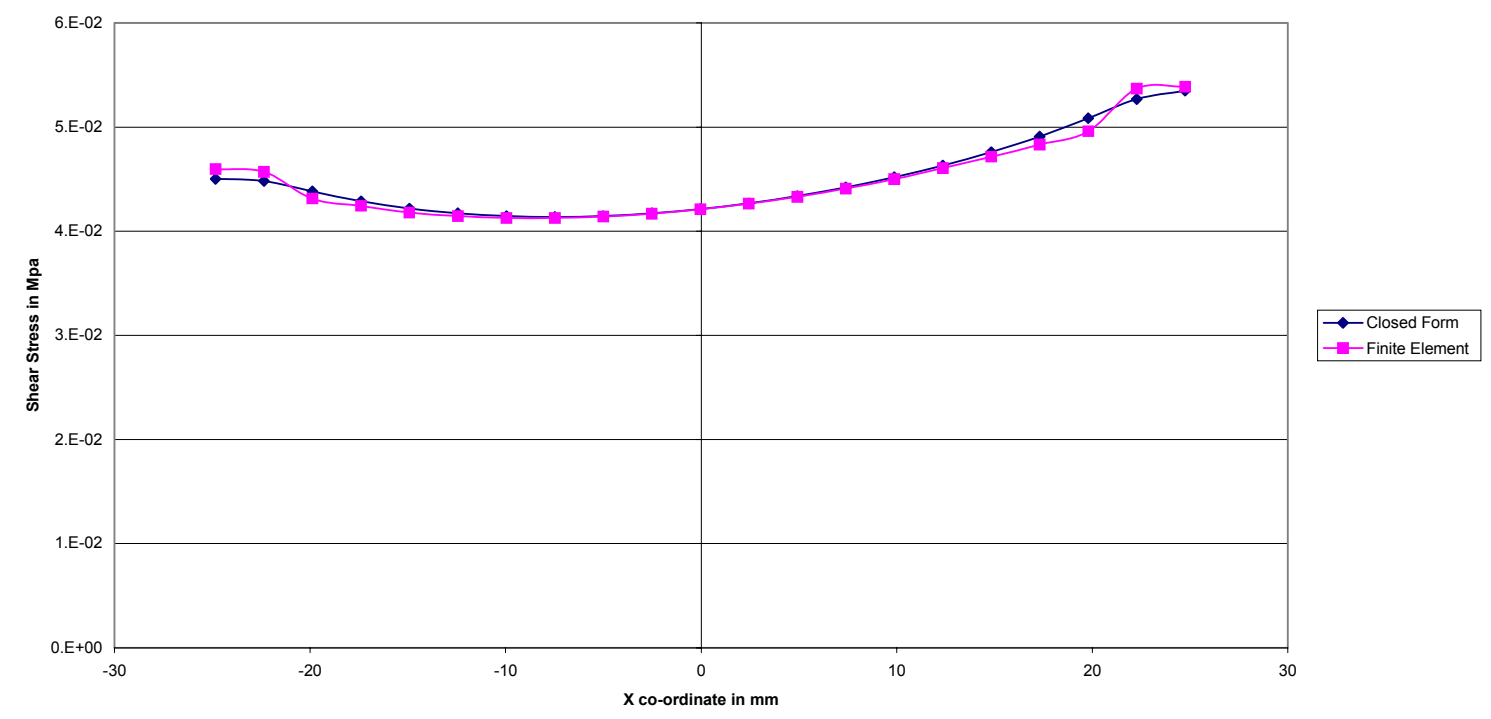

Fig 5.1: Shear Stress in the Adhesive in the Hart-Smith Model

The double lap bonded joint considered by Prucz, is now validated without the extensional link. There is structurally no difference between the Hart-Smith model and model developed by Prucz without the extensional link as mentioned in Chapters 3 and 4. The equations are also similar except that the constant $\beta$ in Prucz model is equal to $\lambda$ times the length in the Hart-Smith's model (equation 5.1).

$\tau(x)=A \sinh (\beta x / l)+B \cosh (\beta x / l)$

The areas in the model are created using key points and lines in ANSYS and at the line of symmetry the joint is constrained in all degrees of freedom. A concentrated force is applied at the free end and the static analysis is performed. The shear stress in the adhesive along the overlap length is plotted and the results are compared with the results from the closed form. The axial stresses in the inner and outer adherends are also plotted along the length and are compared with the results from the closed form solution. The displacements in the inner and outer adherends are also plotted along the overlap length and the results from the finite element match with the results obtained from the closed form. 
Figure 5.2 shows comparison of the shear stress in the adhesive from the closed form and the finite element model for the present model of the double lap joint without the extensional link respectively. The curves from the both the models follow the same profile. But due to the meshing, at the edges it can be observed that the values are higher in the finite element model. Figures 5.3 and 5.4 are the axial stresses and displacements in the outer adherends. The stress in the outer adherend decreases along the bond length and will be minimum at the free end. The axial displacement increases non-linearly along the bond length. Figure 5.5 represents the axial stress in the inner adherend and it increases along the bond length and will be maximum at the free end where the force is applied and the numerical stress value will be equal to the force applied divided by the area of cross section in the inner adherend. This is obtained in the finite element model and thus it can be concluded that the model is validated.

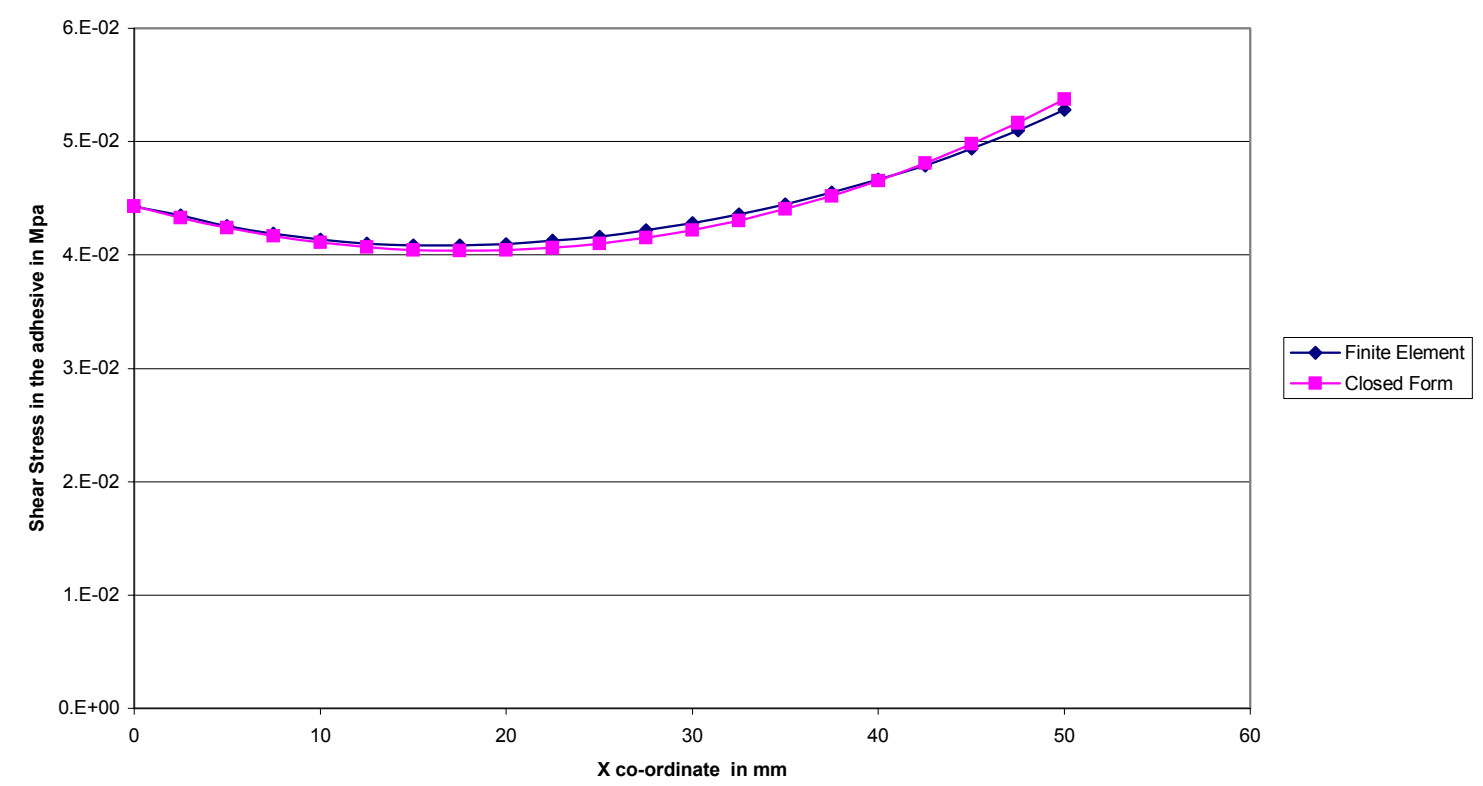

Fig 5.2: Shear Stress in the Adhesive in the Double Lap Joint without Extensional Link 


\subsection{Double Lap Joint with Extensional Link}

As mentioned in the Section 5.4 this model has origin at the beginning of the overlap and also the model has an extensional link which connects the inner adherends at the line of symmetry.

$$
\tau(x)=A \sinh (\beta x / l)+B \cosh (\beta x / l)
$$

The constant $\beta$ is chosen in the present model in the equations as it is a non dimensional quantity. The material properties are used are from reference [1]. The following table gives the list of material properties considered for the adhesive, adherends and the extensional link.

Table 5.2: Material Properties of the Components in the Double Lap Joint with the Extensional Link

\begin{tabular}{|c|c|c|}
\hline Components & Young's modulus (Mpa) & Poisson's ratio \\
\hline Adherend & 107593 & 0.3 \\
\hline Adhesive & 107.588 & 0.3 \\
\hline Extensional Link & 15748.0315 & 0.3 \\
\hline
\end{tabular}

The following quantities were compared in order to validate the finite element model:

- The shear stress in the adhesive was again plotted along the overlap length from both finite element and the closed form models.

- The normal stresses in the inner and outer adherends were plotted along the length of the overlap and both the closed form and the finite element models tally with each other, this can be observed from the graphs. The equations used for the inner and the outer adherends are :

$$
\begin{aligned}
\sigma_{i} & =\left(2 \int \tau(x) d x+C_{i t}\right) / t_{i} \\
\sigma_{o} & =\left(\int \tau(x) d x+C_{o t}\right) / t_{o}
\end{aligned}
$$

Where the constants $\mathrm{C}_{\mathrm{it}}$ and $\mathrm{C}_{\mathrm{ot}}$ are defined in Chapter 3 . 
- The displacements were calculated using equations from the closed form and then were compared to the displacement values obtained from the finite element.

All the graphs plotted showed that both the models gave similar results, which enables the parametric study to be performed on either of them. The following equations were used for the inner and outer adherends respectively:

$$
\begin{aligned}
& u_{i}(x)=\frac{1}{E_{i} t_{i}} \int T_{i}(x) d x+C_{i u} \\
& u_{o}(x)=\frac{1}{E_{o} t_{o}} \int T_{o}(x)+C_{o u}
\end{aligned}
$$

Where the constants $\mathrm{C}_{\mathrm{iu}}$ and $\mathrm{C}_{\mathrm{ou}}$ are defined in the Chapter 3.

Figure 5.6 is the shear stress in the adhesive along the bond length for the double lap joint with extensional link. The shear stress in this model is low when compared to the double lap joint without the extensional link because the extensional link also will share some of the load which is applied on the inner adherend. Figures 5.7 and 5.8 represent the axial stresses and the axial displacements in the outer adherend along the bond length. The stress decreases along the bond length and is minimum at the free end. The displacement is zero at the end where the outer adherends are constrained and then the displacement increases non-linearly along the bond length. Figures 5.9 and 5.10 are the axial stresses and displacements for the inner adherend. The stress increases along the bond length and the displacement also increases along the bond length. 


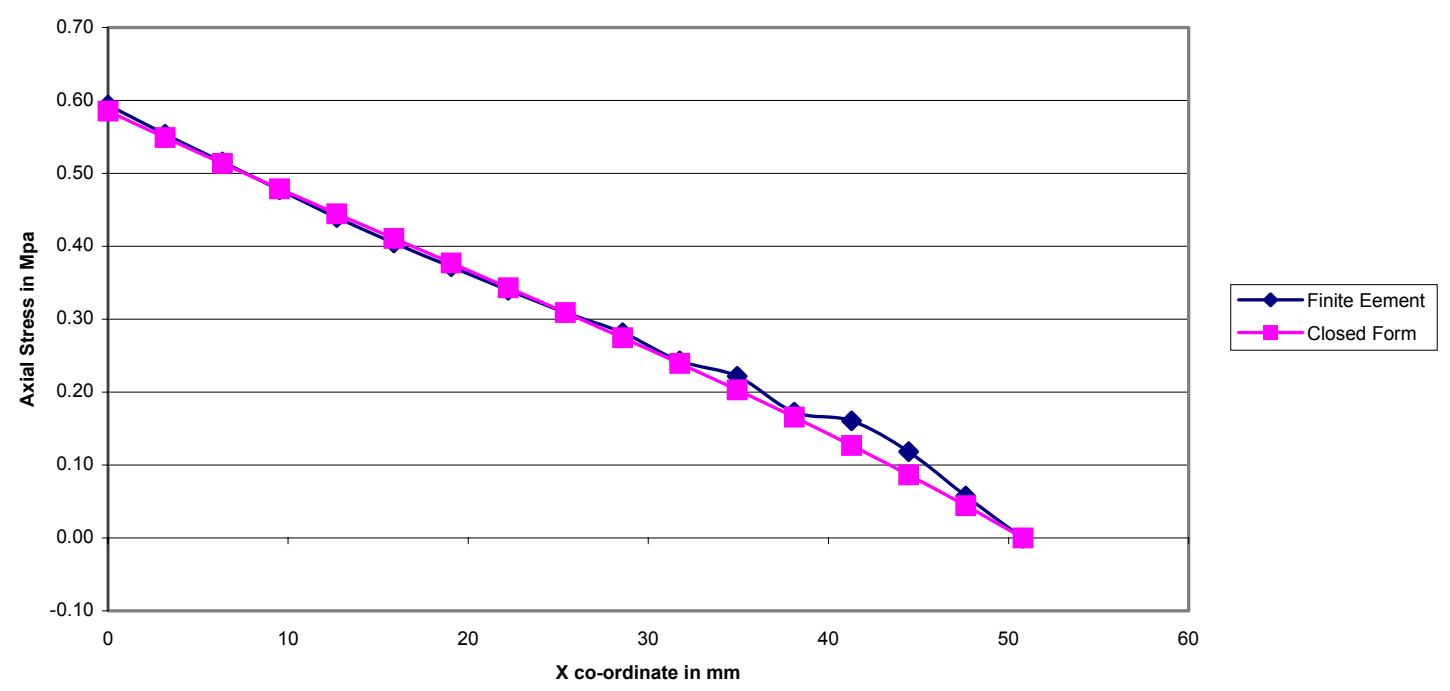

Fig 5.3: Axial Stresses in the Outer Adherend without the extensional link

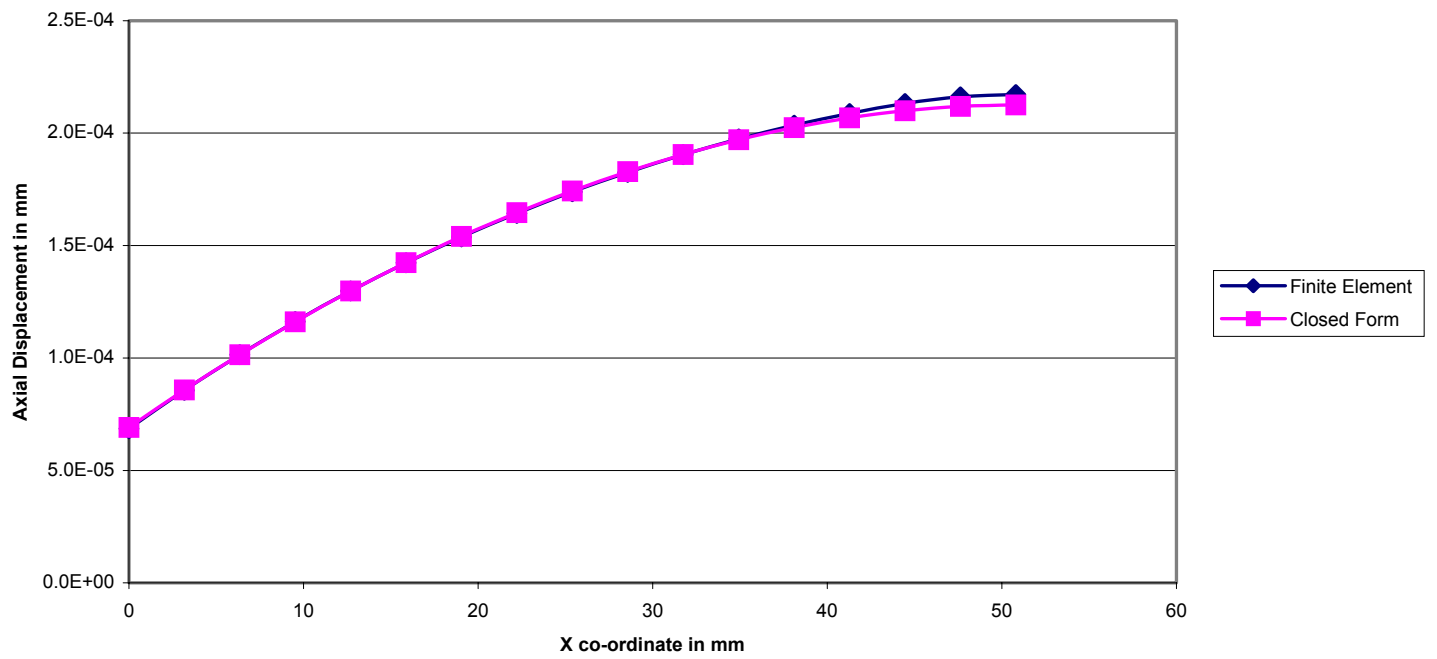

Fig 5.4: Axial Displacements in Outer Adherend without the extensional link 


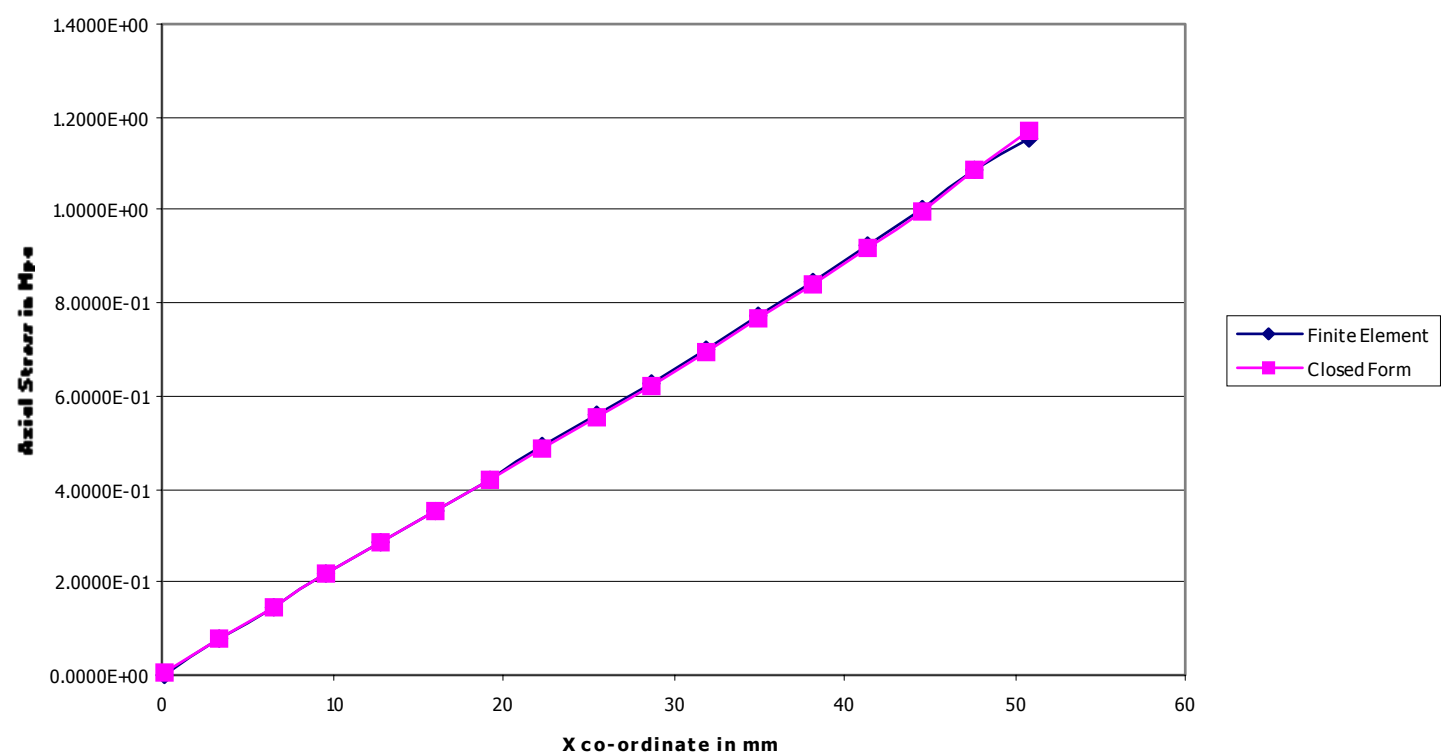

Fig 5.5: Axial Stress in the Inner Adherend for the Double Lap Joint without the Extensional Link

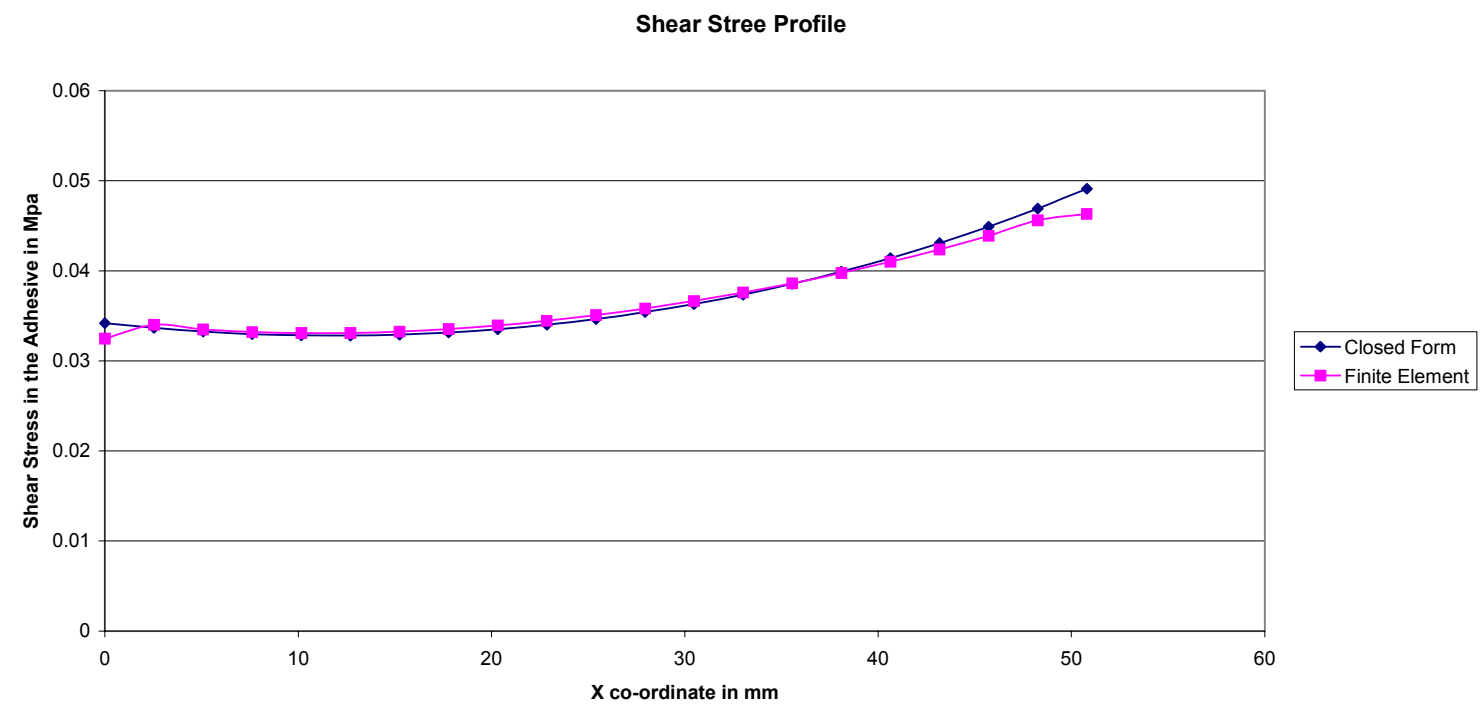

Fig 5.6: Shear Stress in the Double Lap Joint with Extensional Link 


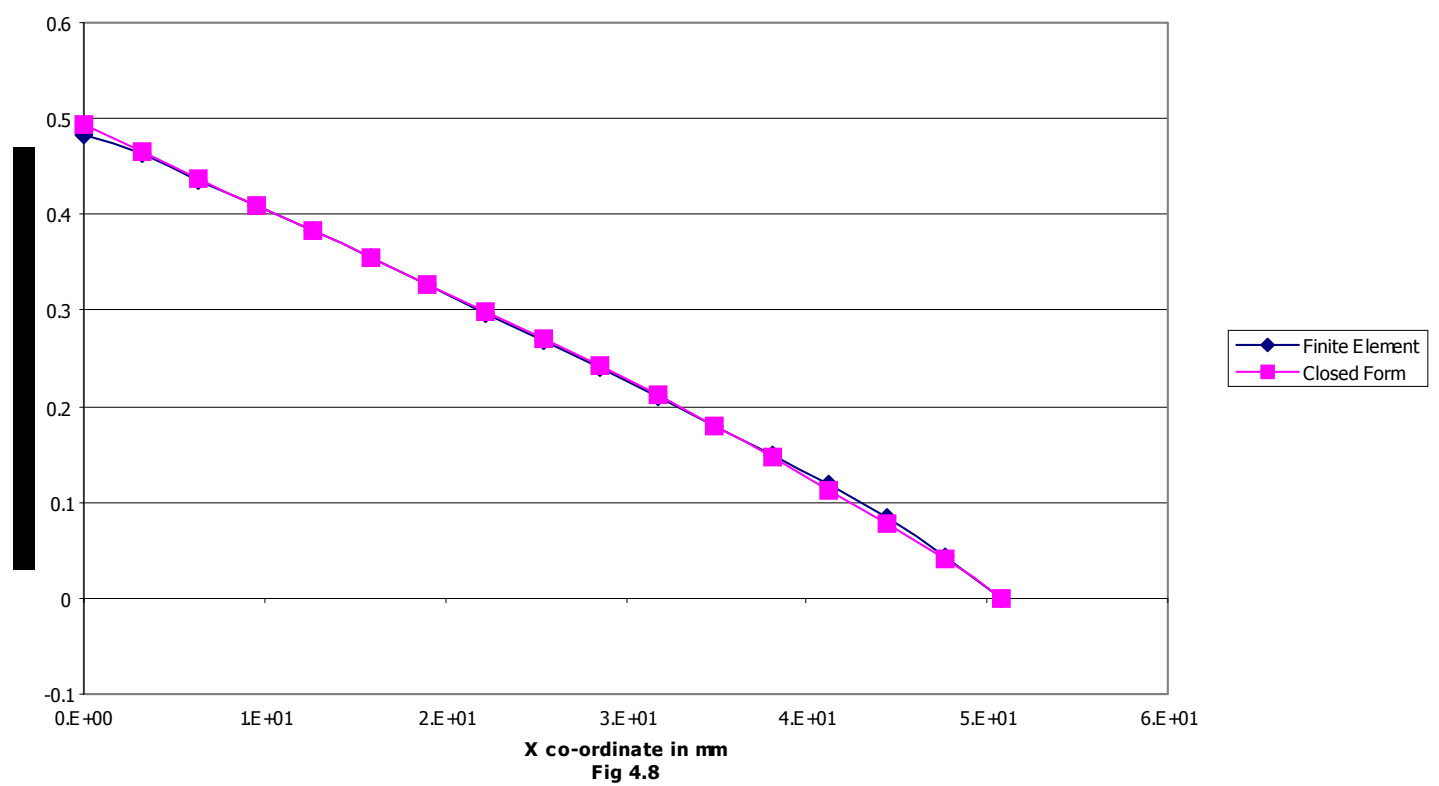

Fig 5.7: Axial Stress in the Outer Adherend for the Double Lap Joint with Extensional Link

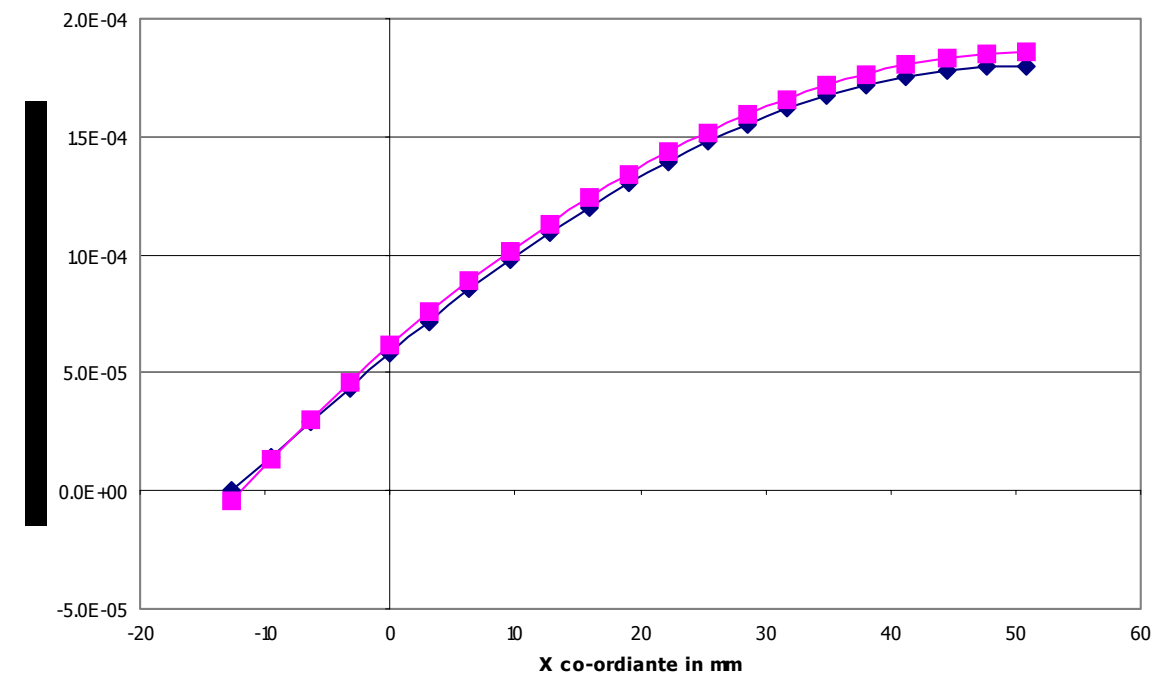

$\multimap-$ Finite Element $\longrightarrow$ - Closed Form

Fig 5.8: Displacement of the Outer Adherend in the Double Lap Joint with Extensional Link 


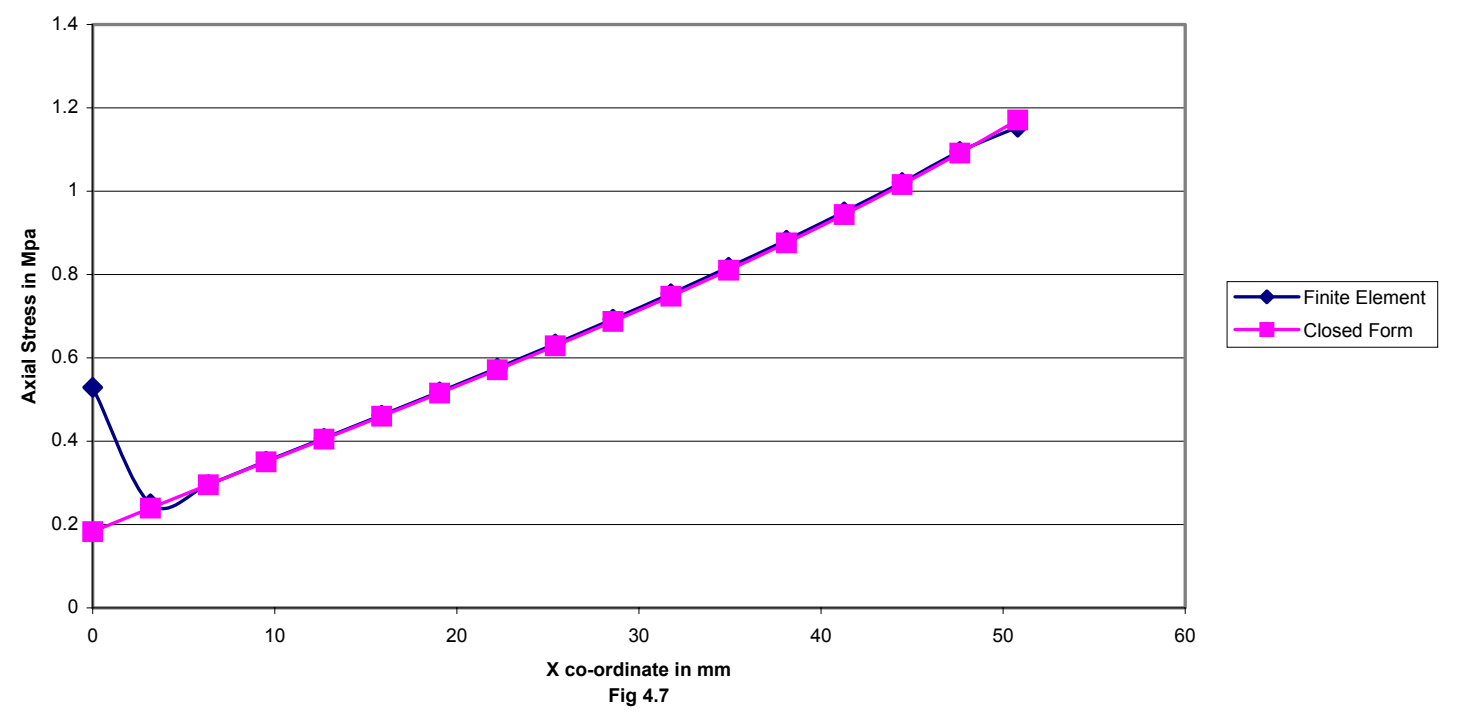

Fig 5.9: Axial Stress in the Inner Adherend with the Double Lap Joint with the Extensional Link

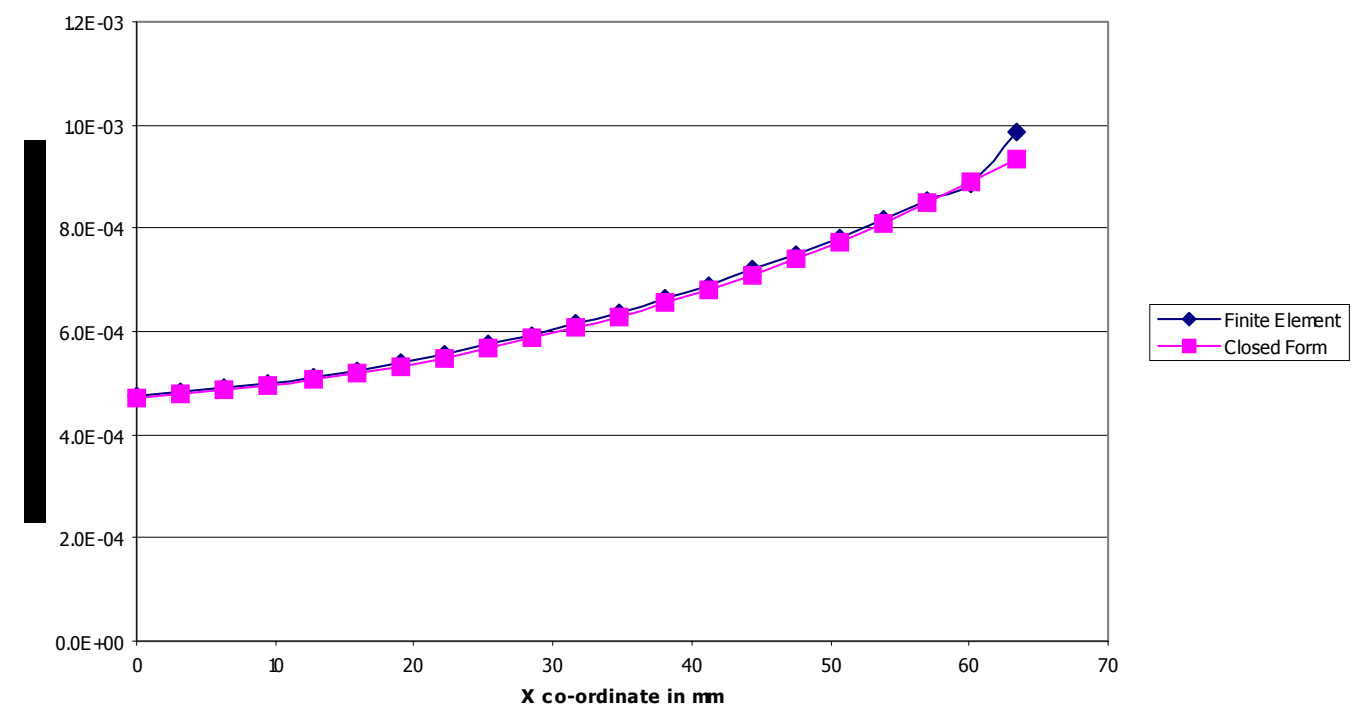

Fig 5.10: Displacement in the Inner Adherend in the Double Lap Joint with Extensional Link 


\section{CHAPTER 6: PARAMETRIC ANALYSIS}

In this chapter different parameters that characterize a double lap bonded joint are changed and the structural behavior of the joint is analyzed in terms of stress and displacement responses. There are two types of parameters, which can be considered for structural analysis. They are

- Geometric Parameters

- Material Parameters

Geometric parameters include the thickness of the adhesive and the adherends, the length of the overlap. Material parameters include different material properties for the adhesive, adherends and also for the extensional link.

Depending on the complexity of the geometry the closed form model or the finite element model are chosen to perform parametric analysis of the double lap bonded joint. Section 6.1 describes the parametric studies performed with the closed form model and Section 6.2 describes the parametric studies performed with the finite element model.

\subsection{Parametric Studies Based on the Closed Form Model}

In this section the closed form model is considered for the parametric study.

\section{a) Effect of Overlap Length}

The overlap length, which is one of most important geometric parameters, is varied and simultaneously the stiffness of the extensional link is also varied. Figs 6.1 to 6.4 depict plots of shear distributions for different overlap lengths and also for different stiffness values of the extensional link. The baseline overlap length considered in the validation of the closed form model by using the finite element analysis was chosen to be equal to $50.8 \mathrm{~mm}$. In the parametric analysis four different overlap lengths are considered ranging from $12.7 \mathrm{~mm}$ to $50.8 \mathrm{~mm}$ with an increment of $12.7 \mathrm{~mm}$. The shear stress distribution in the adhesive along the overlap length was plotted for these overlap lengths for different stiffness values of the extensional link. Fig 6.1 shows the profile of the shear 
stress for the overlap length $50.8 \mathrm{~mm}$ for different range of stiffness values for the extensional link. The shear stress distribution in the adhesive is non-linear along the overlap length and is maximum at the free edge of the joint. The maximum shear stress in the adhesive decreases with the increase in overlap length. This happens because the increase in overlap length implies an increase in the bond area, which means that the contact force is distributed over a larger area and thus the magnitude of the associated values of the shear stress in the adhesive decreases. Table 6.1 describes the effect of overlap length on the maximum values of the shear stress in the adhesive.

Table 6.1: Effect of Overlap Length

\begin{tabular}{|c|c|}
\hline \% Increase in the Overlap Length & \% Decrease in the Maximum Shear Stress \\
\hline 100 & 31.491 \\
\hline 200 & 45.124 \\
\hline 300 & 52.251 \\
\hline
\end{tabular}

The tension applied on the joint, denoted by ' $\mathrm{P}$ ' is increased gradually from $50 \mathrm{~N}$ to $500 \mathrm{~N}$ with and increment of $50 \mathrm{~N}$ and maximum shear stress in the adhesive is plotted for different values of the stiffness of the extensional and also for different overlap lengths. The variation in the maximum shear stress decreases as the overlap length increases. Since the maximum shear stress is directly proportional to the force applied, the curves exhibit linear behavior (Fig 6.2). For small magnitudes of the applied force the shear stress is nearly unchanged for different stiffness values of the extensional link.

Fig 6.3 depicts the variation of the maximum shear stress in the adhesive with the overlap length for different values of applied tension. Overlap lengths ranging from $10 \mathrm{~mm}$ to $55 \mathrm{~mm}$ are considered and it can be observed from graph that the decrease in the maximum shear stress with the increase in overlap length is non-linear.

Fig 6.4 depicts the variation of the maximum shear stress in the adhesive with the overlap length for different values of the stiffness of the extensional link. For low 
stiffness values of the extensional link, the decrease in the maximum shear stress with the increase in overlap length is more with respect to high stiffness values of extensional link.

\section{b) Effect of Stiffness of the Extensional Link}

When the ratio between the stiffness of the extensional link and the shear modulus of the adhesive is 1 , the effect of the extensional link is negligible. The minimum ratio at which there is a considerable effect is 4 . Therefore, an initial value of the stiffness of the extensional link is considered to be four times the shear modulus of the adhesive and this base value is increased 5 and 10 times for further analysis. Also, the value considered by Prucz [1] is included in the present analysis. The effect of the stiffness of the extensional link on the maximum shear stress in the adhesive is more pronounced for small overlap lengths but it diminishes as the length of the overlap increases.

A tension of $500 \mathrm{~N}$ was applied on the inner adherend for various values of the overlap lengths. The coupled effects of the overlap length and the stiffness of the extensional link on the maximum shear stress in the adhesive are shown in Table 6.2.

Table 6.2: Effect of Stiffness of the Extensional Link

\begin{tabular}{|c|c|c|}
\hline Overlap Length in $\mathrm{mm}$ & $\begin{array}{c}\text { \% Increase in the stiffness } \\
\text { of the extensional link }\end{array}$ & $\begin{array}{c}\text { \% Decrease in the } \\
\text { maximum shear stress in the } \\
\text { adhesive }\end{array}$ \\
\hline 12.7 & 12.2 & 4.7 \\
\hline 25.4 & 12.2 & 2.51 \\
\hline 38.1 & 12.2 & 1.56 \\
\hline 50.8 & 12.2 & 1.01 \\
\hline
\end{tabular}

Fig 6.5 depicts the relation between the stiffness of the extensional link and the maximum shear stress for different overlap lengths. The decrease in the value of maximum shear stress is quite linear with the increase in the stiffness of the extensional link. 


\section{c) Effect of the Thickness of the Adhesive}

The thickness of the adhesive is also varied in order to observe its effect on distribution of the shear stress in the adhesive along the overlap length. The results are illustrated in Fig 6.6 for an overlap length of $50.8 \mathrm{~mm}$ and a range of variation in the thickness of the adhesive from $0.2 \mathrm{~mm}$ to $1.5 \mathrm{~mm}$. From the graph it may be noticed that the shear stress distribution in the adhesive becomes uniform along the overlap length as the thickness of the adhesive increases. The maximum shear stress in the adhesive decreases as the thickness of the adhesive increases, as they are inversely proportional to each other.

\section{d) Effect of Adherend Properties}

Three different choices of adherends with different material properties are considered in this study the shear stress distribution in the adhesive is plotted for every corresponding value of the Young's modulus, E. It is observed from the Fig 6.7 that as the stiffness of the adherend increases the maximum shear stress in the adhesive decreases.

\subsection{Parametric Studies Based on the Finite Element Model}

The finite element model has been used for the parametric analysis, of joint characteristics that are not considered in the closed form of the model.

\section{a) Effect of Tapering}

The finite element model described in chapter 4 has been verified by comparing its results with those obtained from the closed form model. Therefore the finite element model of the joint can be used for any parametric analyses. The most important advantage of this model is that it can be used with confidence for any type of geometry of the adhesives and the adherends. Such a task would be very complex to perform by using the equations of the closed form model. In this section the parametric analysis is performed for two main types of joint configurations:

- The outer adherends are tapered at an angle $45^{\circ}$.

- A spew fillet is included in the adhesive 
In the first case no extensional link is considered, and the edges of the outer adherends are tapered at an angle $45^{\circ}$. Fig 6.8 depicts the finite element model of such a joint. The material properties utilized for this model given in Table 5.1. The boundary conditions are similar to those applied on the model in chapter 4. It can be observed from Fig 6.9 that the shear stress in the adhesive does no longer reach its maximum value at the free edge when the adherends are tapered. The stress at the free edge is reduced therefore due to the tapering; the comparison between the tapered and the non-tapered adherends can be observed from the Fig 6.9.

"Spew fillet is referred to as the excess portion of adhesive squeezed out from the overlap area" [16]. Fig 6.10 is the depiction of the finite element model which is created such that the excess adhesive is tapered at an angle of $135^{\circ}$ with the inner adherend and makes an angle of $45^{\circ}$ with the outer adherend. The shear stresses in the adhesive are smaller for the model with the spew fillet when compared with the model without the spew fillet. The shear stress at the end of the free edge in the adhesive of the joint without fillet is 5.28E-02 Mpa whereas in the joint with fillet the edge shear stress is $1.9 \mathrm{E}-02$ Mpa, less than half of its value in the absence of the spew fillet which can be observed from the Fig 6.11.

\section{b) Comparisons between Single Lap versus Double Lap Configurations}

Fig 6.12 represents the finite element model of a single lap bonded joint. The material properties are taken from Reference [18]. Table 6.3 presents the material properties of the adhesive and the adherend.

Table 6.3: Material Properties for Single Lap Bonded Joint

\begin{tabular}{|c|c|c|}
\hline Components & Young's Modulus in Mpa & Poisson's Ratio \\
\hline Adherend & 107593 & 0.3 \\
\hline Adhesive & 3400 & 0.38 \\
\hline
\end{tabular}

The adhesive considered in this study is Isophthalic, and the shear strength of this adhesive is $75.9 \mathrm{Mpa}$. In this section the maximum applied force is plotted for different 
overlap lengths for both single and double lap bonded joints and the results are compared. Fig 6.13 is a comparison between the effect of overlap length on the maximum allowable force for the single and double lap-bonded joints without extensional link. It can be observed that the maximum allowable force increases linearly with the increase in the overlap length for the single lap whereas for the double lap joint the maximum allowable force increases nonlinearly with the increase in the overlap length. Table 6.4 gives the percentage increase in the maximum allowable force with the percentage increase in the overlap length.

Table 6.4: Effect of Overlap Length on the Single and Double Lap Bonded Joints

\begin{tabular}{|c|c|c|}
\hline $\begin{array}{c}\text { \% Increase in the Overlap } \\
\text { Length. }\end{array}$ & $\begin{array}{c}\text { \% Increase in the Maximum } \\
\text { Allowable Force for the } \\
\text { Single Lap Bonded Joint }\end{array}$ & $\begin{array}{c}\text { \% Increase in the Maximum } \\
\text { Allowable Force for the } \\
\text { Double Lap Bonded Joint }\end{array}$ \\
\hline 100 & 17.5 & 30.30 \\
\hline 200 & 32.5 & 48.49 \\
\hline 300 & 58.75 & 57.58 \\
\hline
\end{tabular}

Fig 6.14 is the plot for the effect of overlap length on the maximum allowable force for single and double lap-bonded joints with extensional link. It can be observed that as the adhesive used is stiff, the effect of extensional link on the double lap joint is negligible. But for the single lap joint the maximum allowable force increases with the increase in the stiffness of the extensional link. The variation of maximum allowable force with the variation of overlap length is plotted in Fig 6.15 for single lap joints with and without an extensional. As one could expect, the extensional link can increase the maximum force that can be transferred without failure through a bonded joint, especially of the single-lap configuration. 


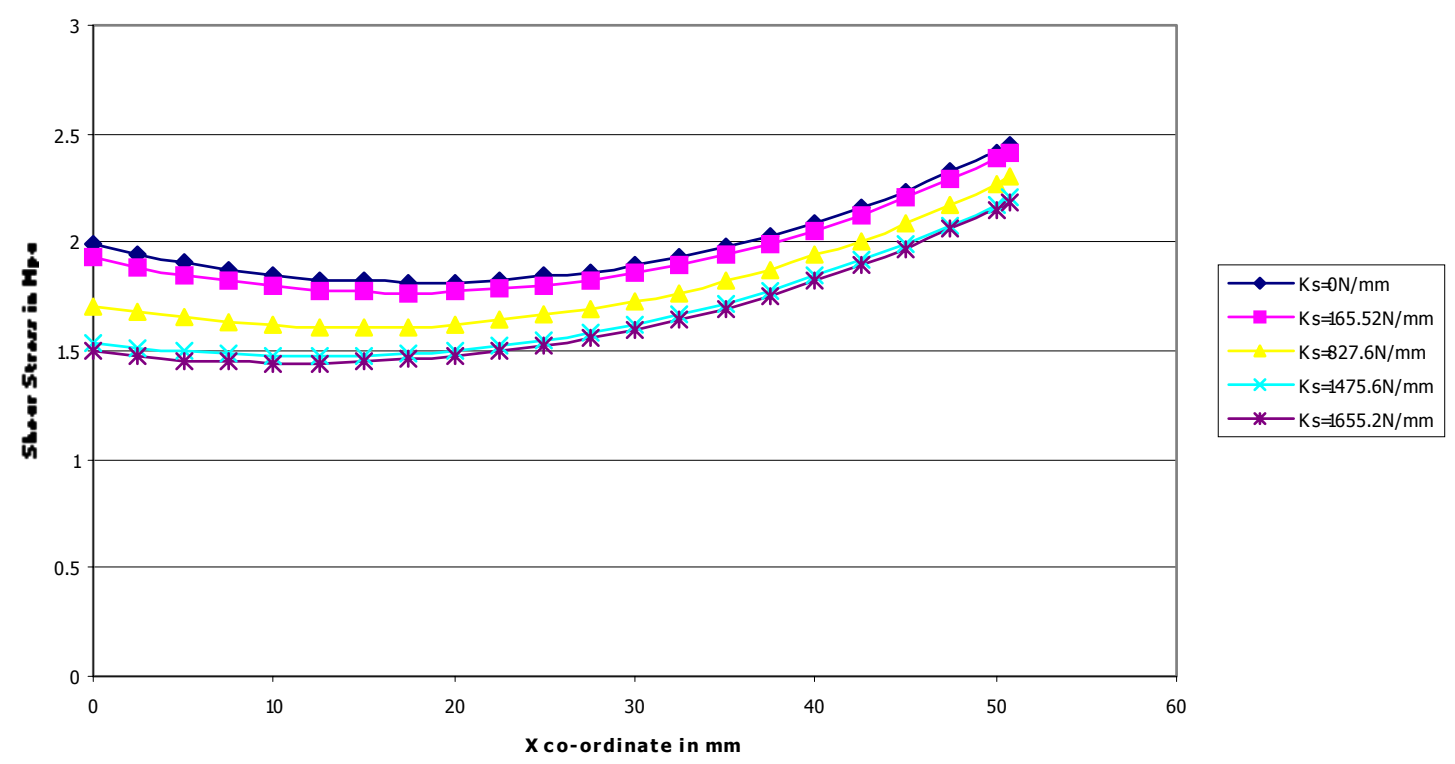

Fig 6.1: Shear Stress in the Adhesive for Overlap Length $=\mathbf{5 0 . 8} \mathbf{~ m m}$

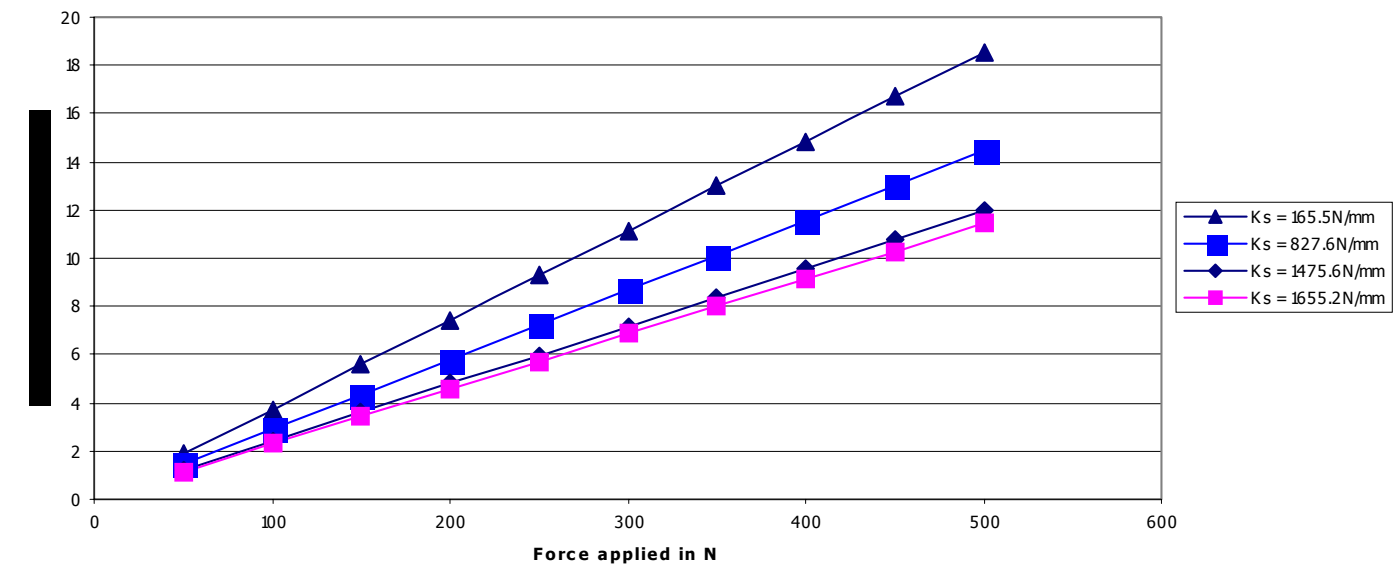

Fig 6.2: Variation of the Maximum Shear Stress in the Adhesive with the Tension Applied on the Joint ( $\mathrm{L}=\mathbf{1 2 . 7} \mathrm{mm})$ 


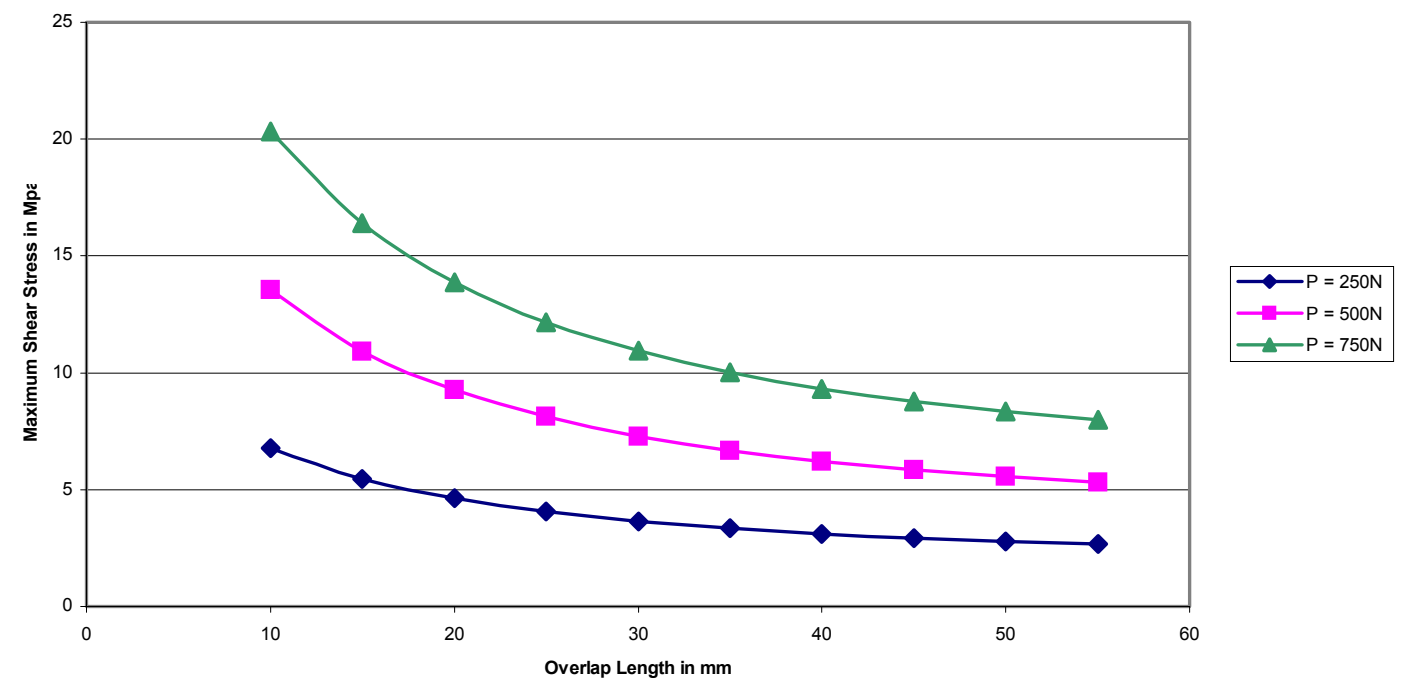

Fig 6.3: Variation of Maximum Shear Stress with the Overlap Length for Different Tensile Forces

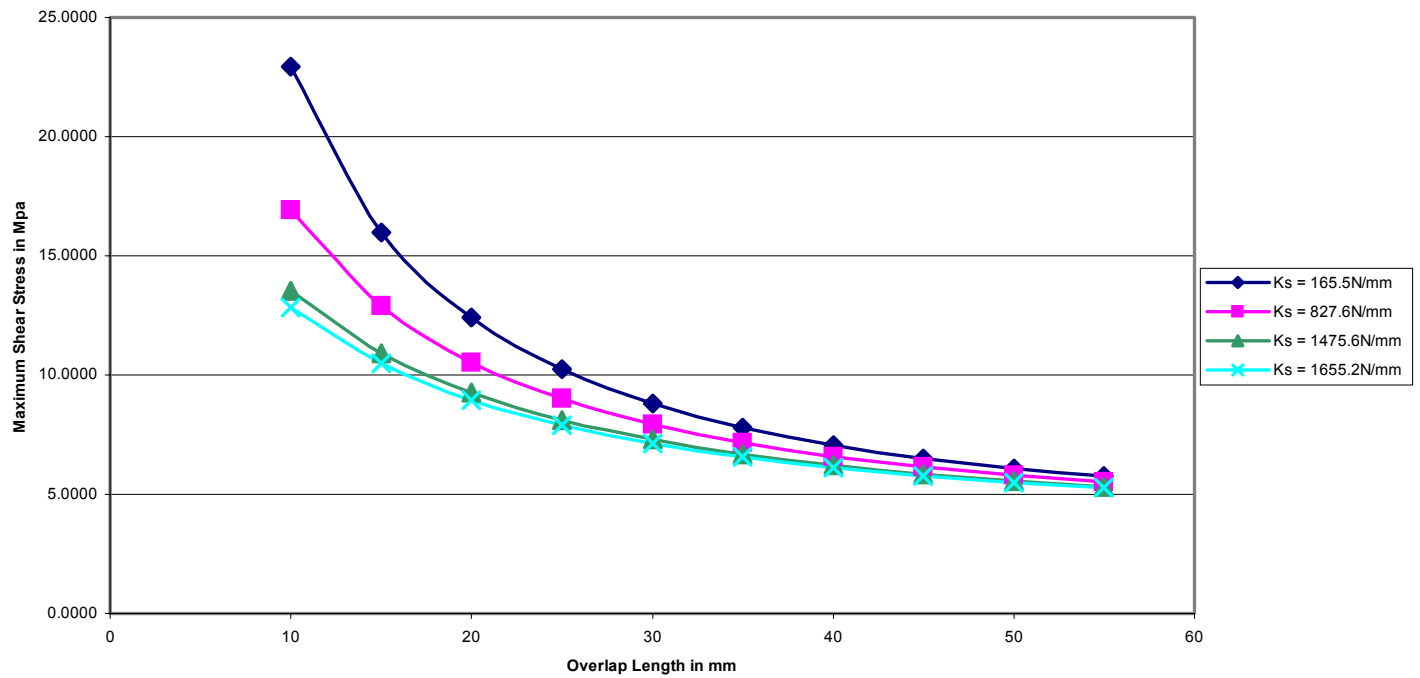

Fig 6.4: Variation of Maximum Shear Stress with the Overlap Length for Different Stiffness Values of the Extensional Link 


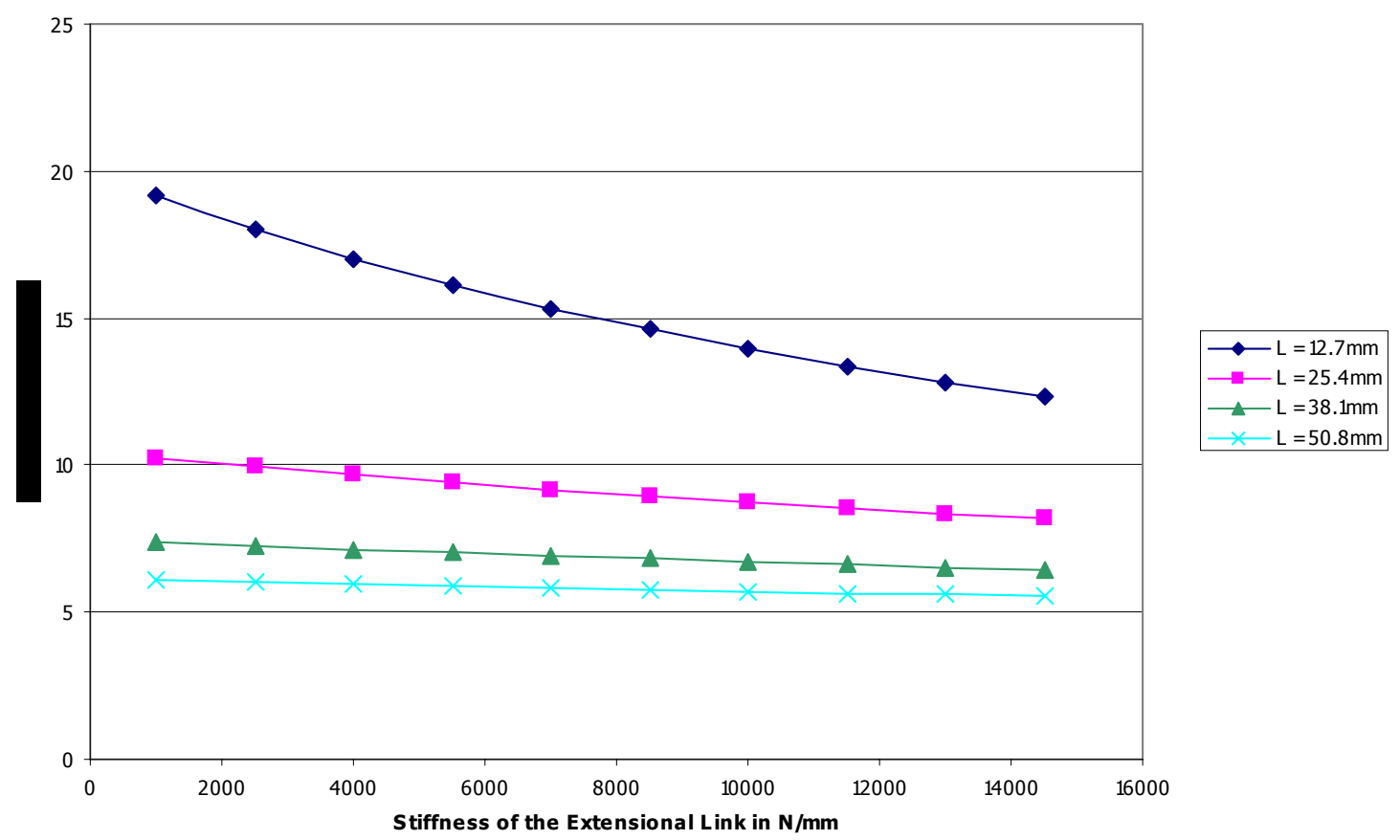

Fig 6.5: Variation of Maximum Shear Stress with Stiffness of the Extensional Link for Different Overlap Lengths

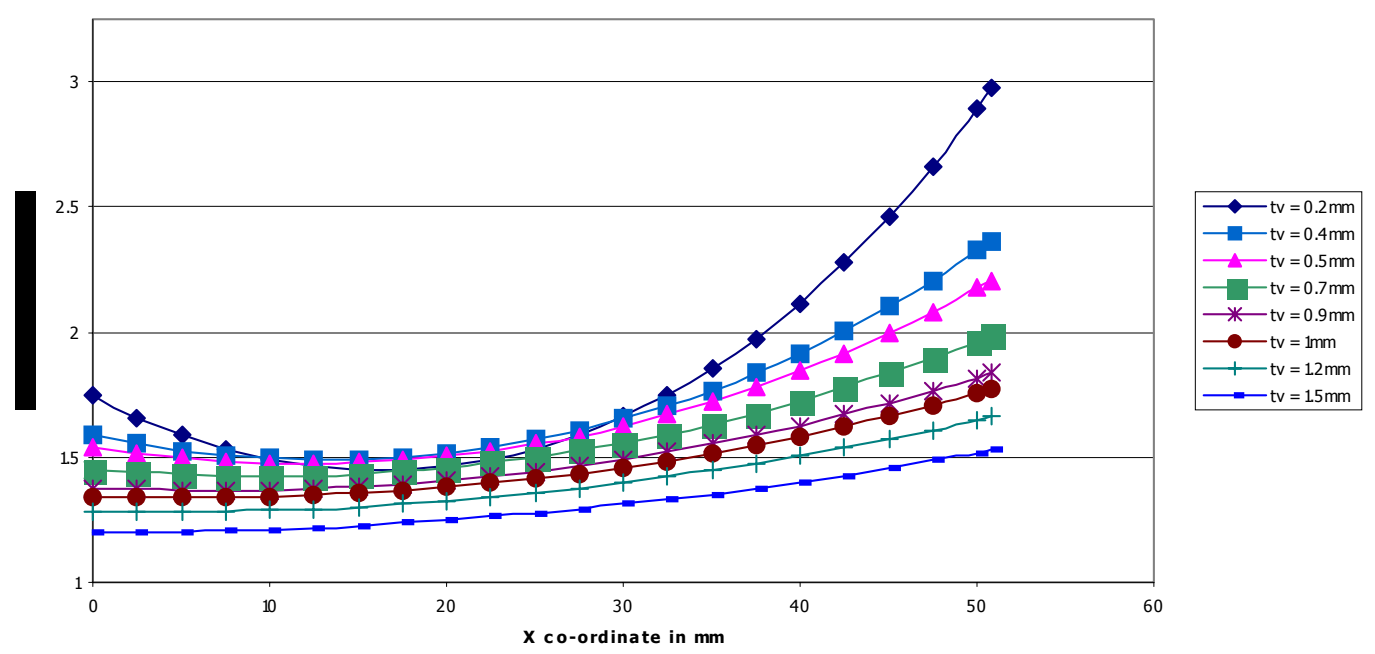

Fig 6.6: Shear Stress of the Adhesive for Overlap Length $L=50.8$ for Different Thickness of Adhesive 


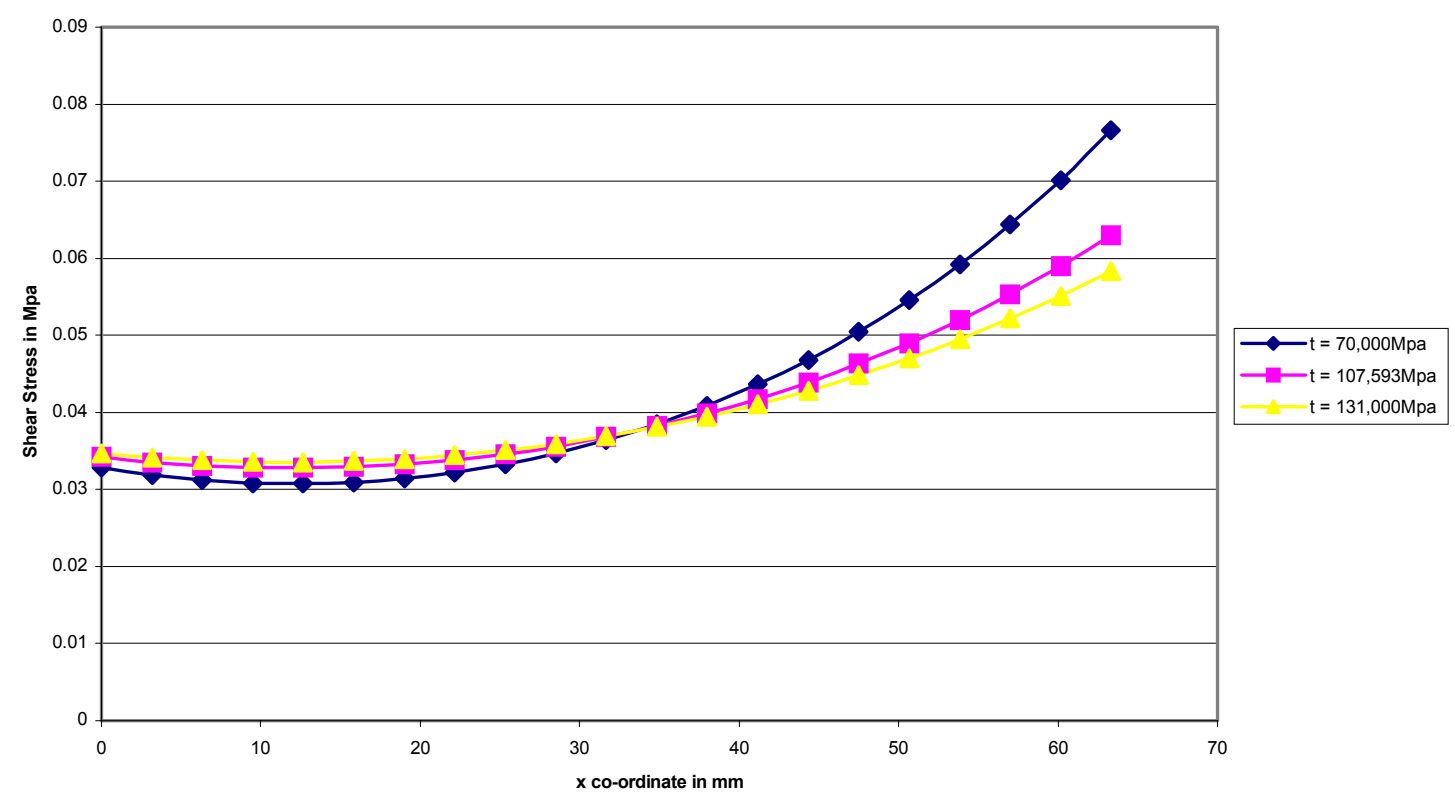

Fig 6.7: Shear Stress Distribution in the Adhesive for Different Adherend Materials

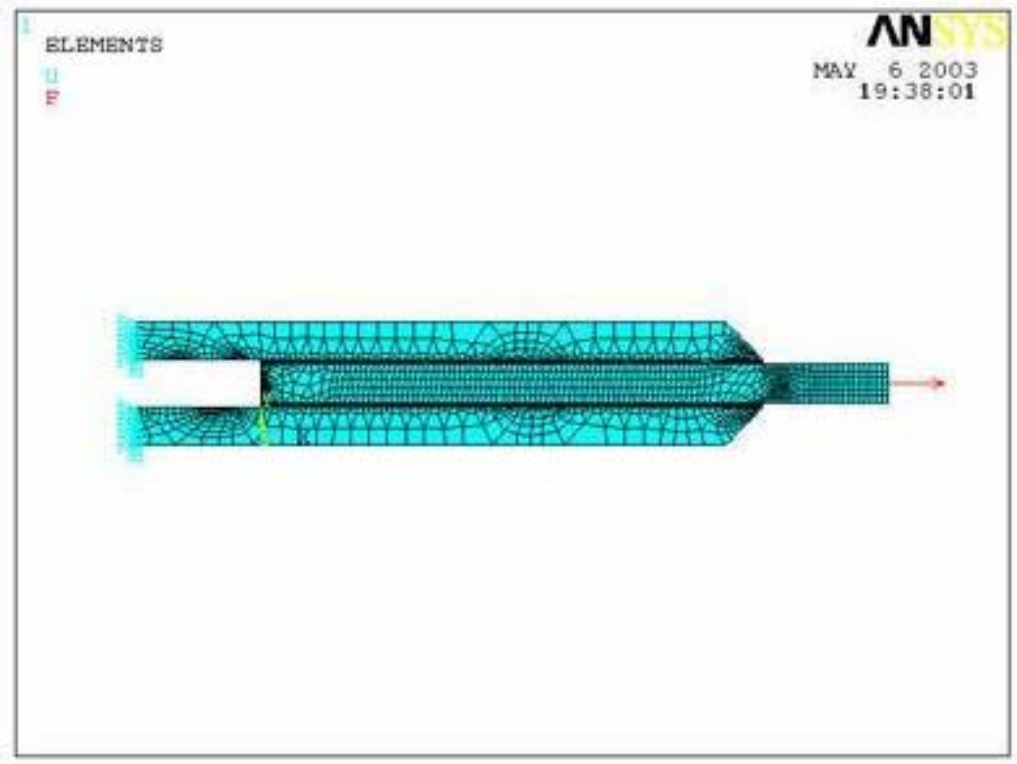

Fig 6.8: Finite Element Model of Double Lap Joint with the Outer Adherends Tapered at an Angle 45 


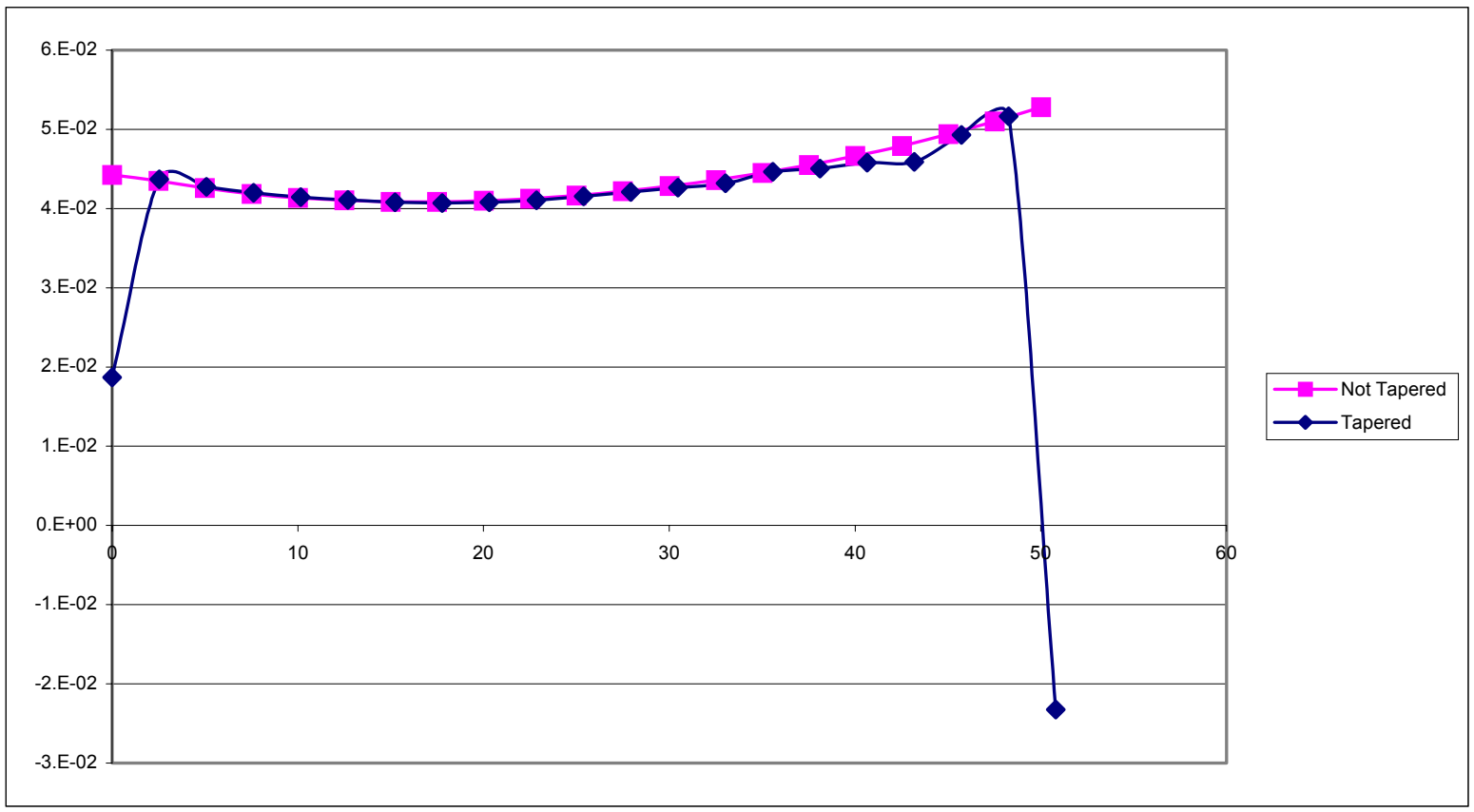

Fig 6.9: Shear Stress Distribution in the Adhesive for the Adherend with Tapered Edge

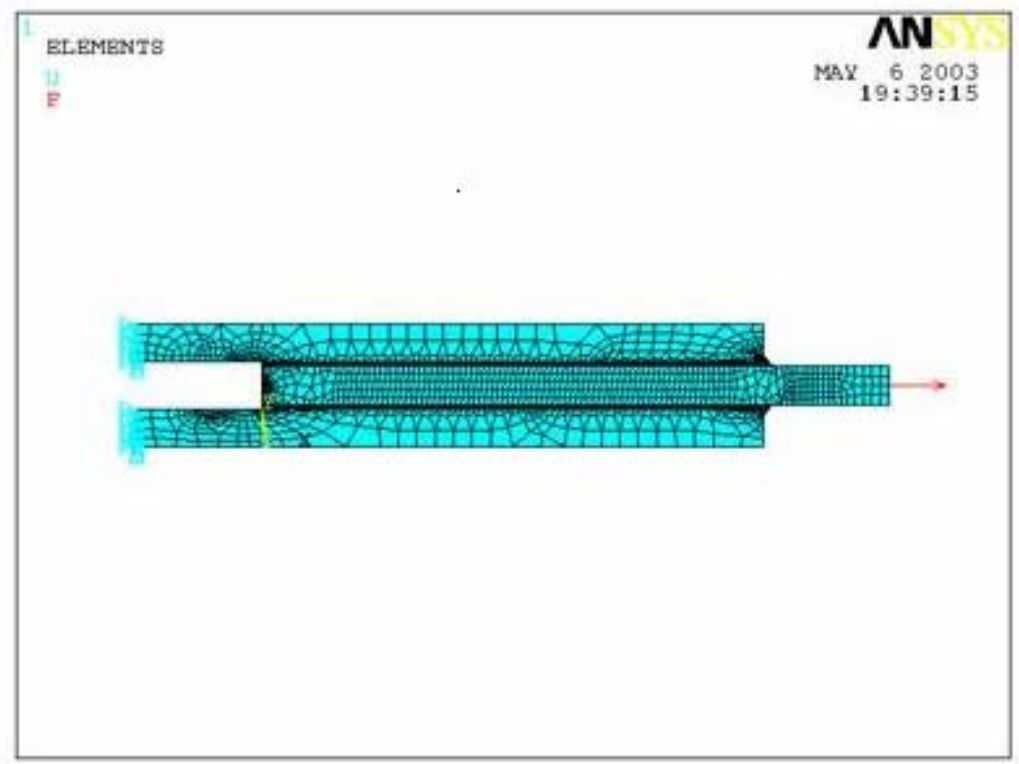

Fig 6.10: Spew Fillet Finite Element Model of the Double Lap Joint 


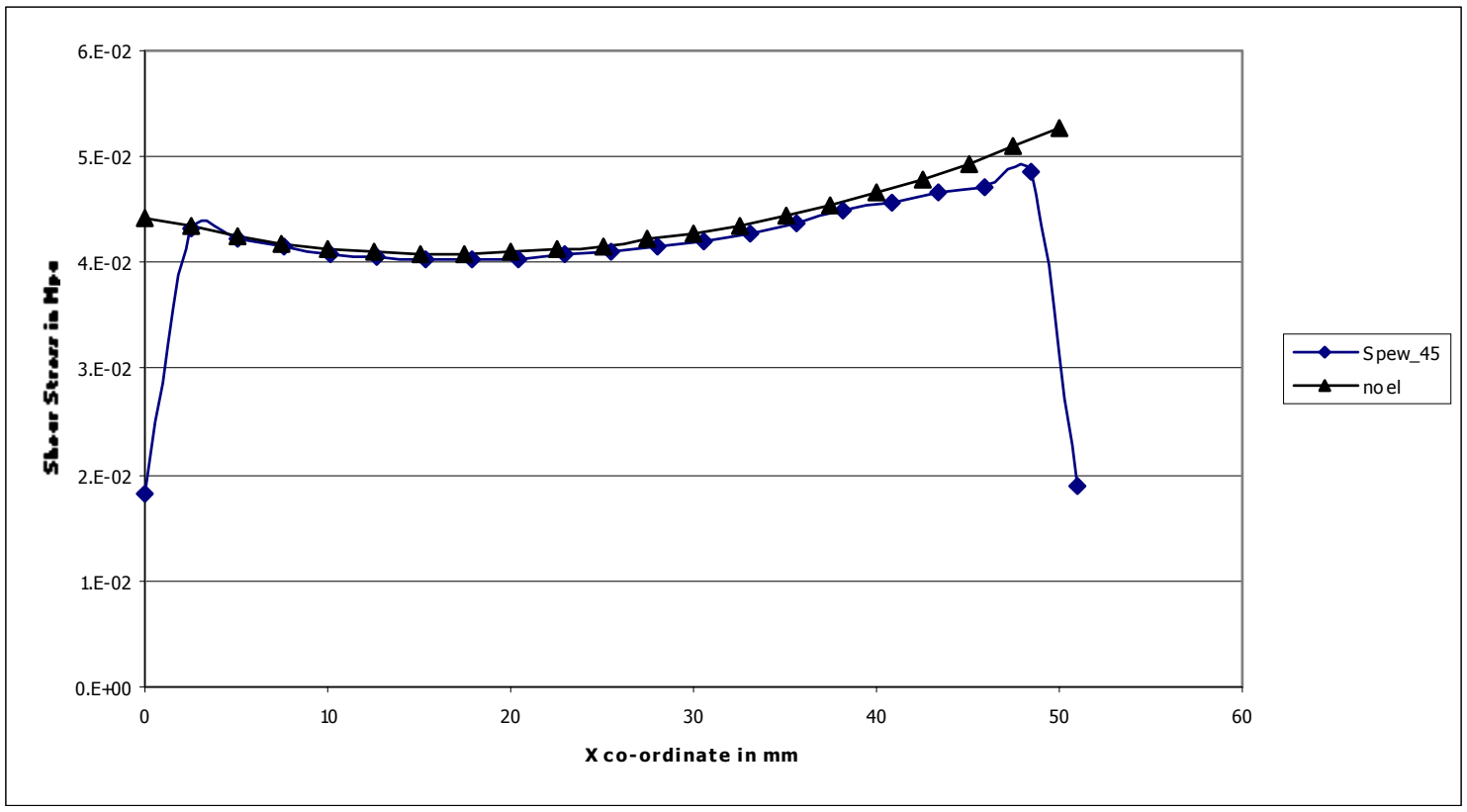

Fig 6.11: Distributions of Shear Stress in the Adhesive of a Double Lap Joint in the Presence and Absence of Spew Fillet

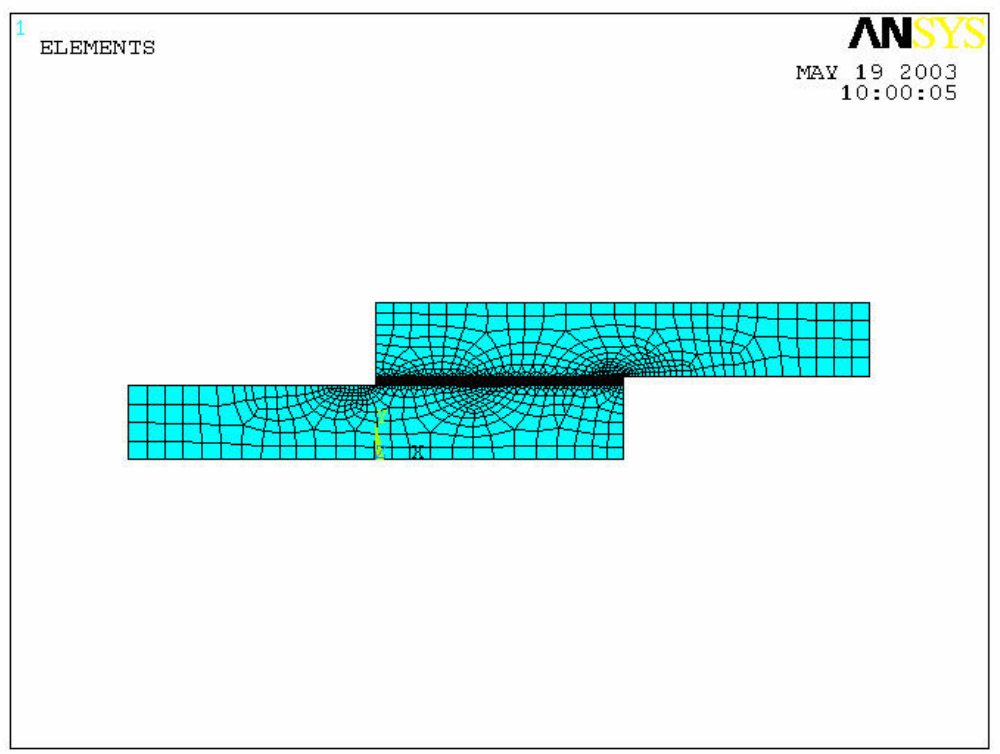

Fig 6.12: Finite Element Model of Single Lap Joint 


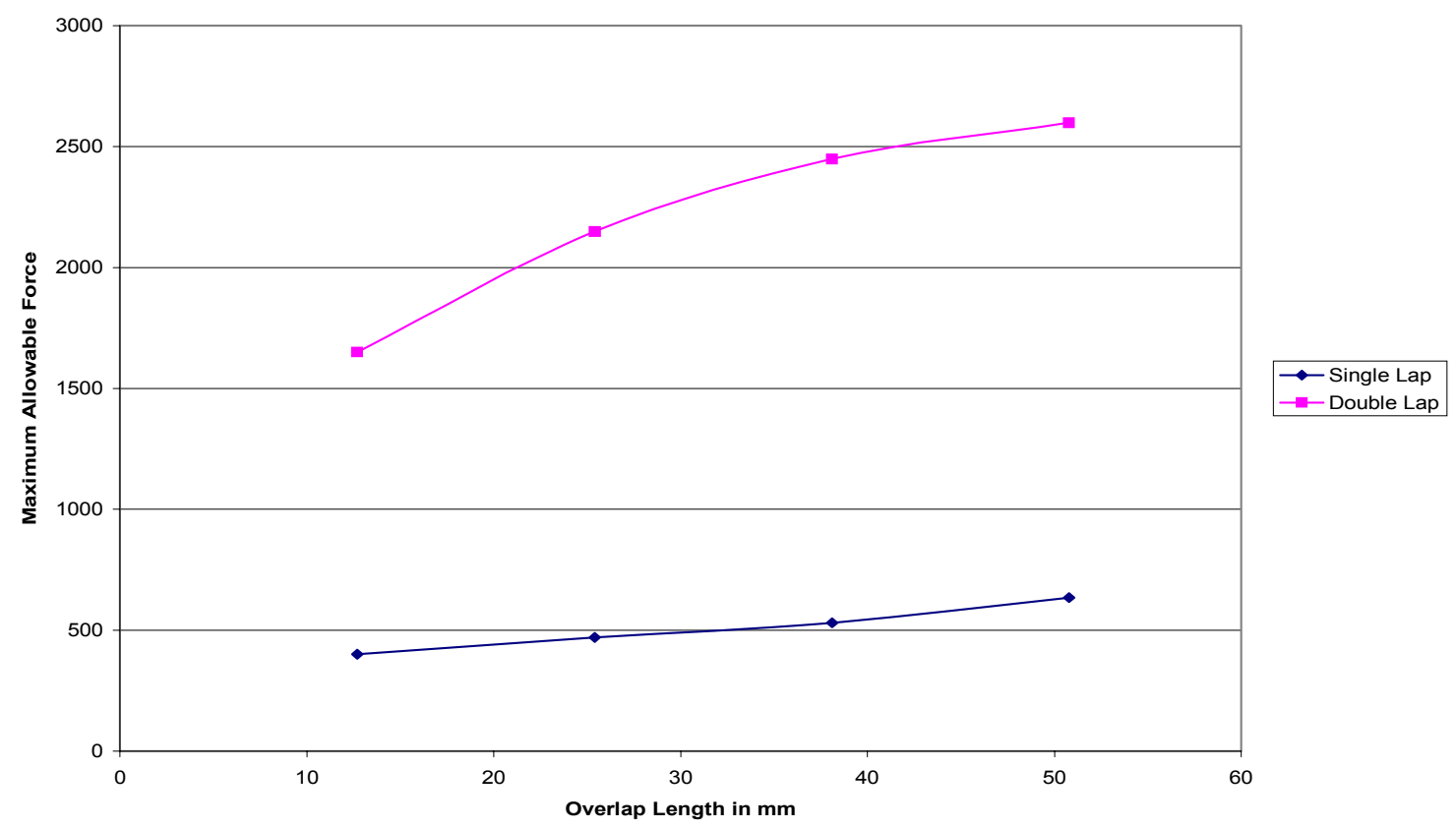

Fig 6.13: The Effect of Overlap Length on the Maximum Allowable Force for Single and Double Lap Bonded Joint without Extensional Link

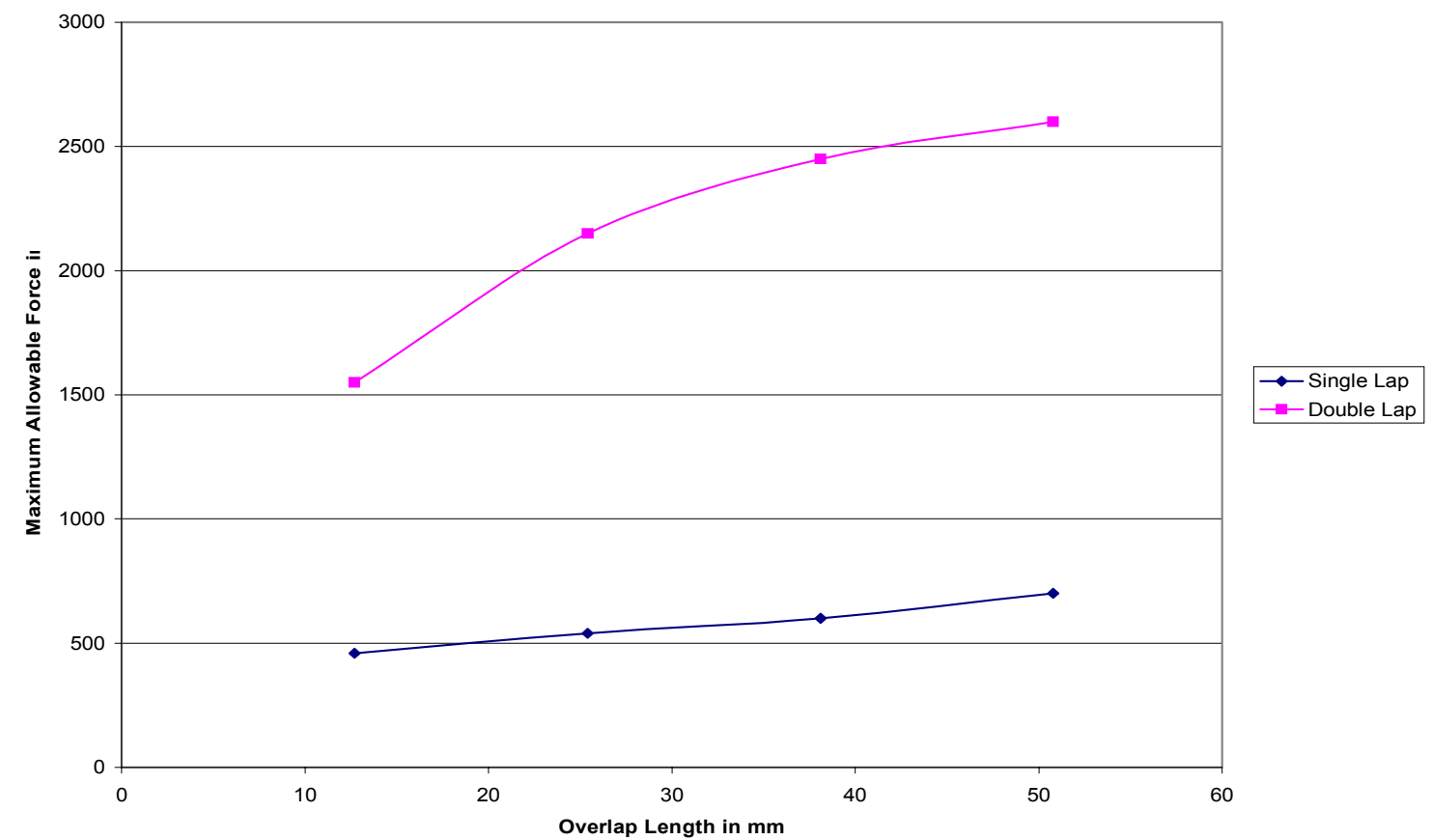

Fig 6.14: The Effect of Overlap Length on the Maximum Allowable Force for Single and Double Lap Bonded Joint with Extensional Link 


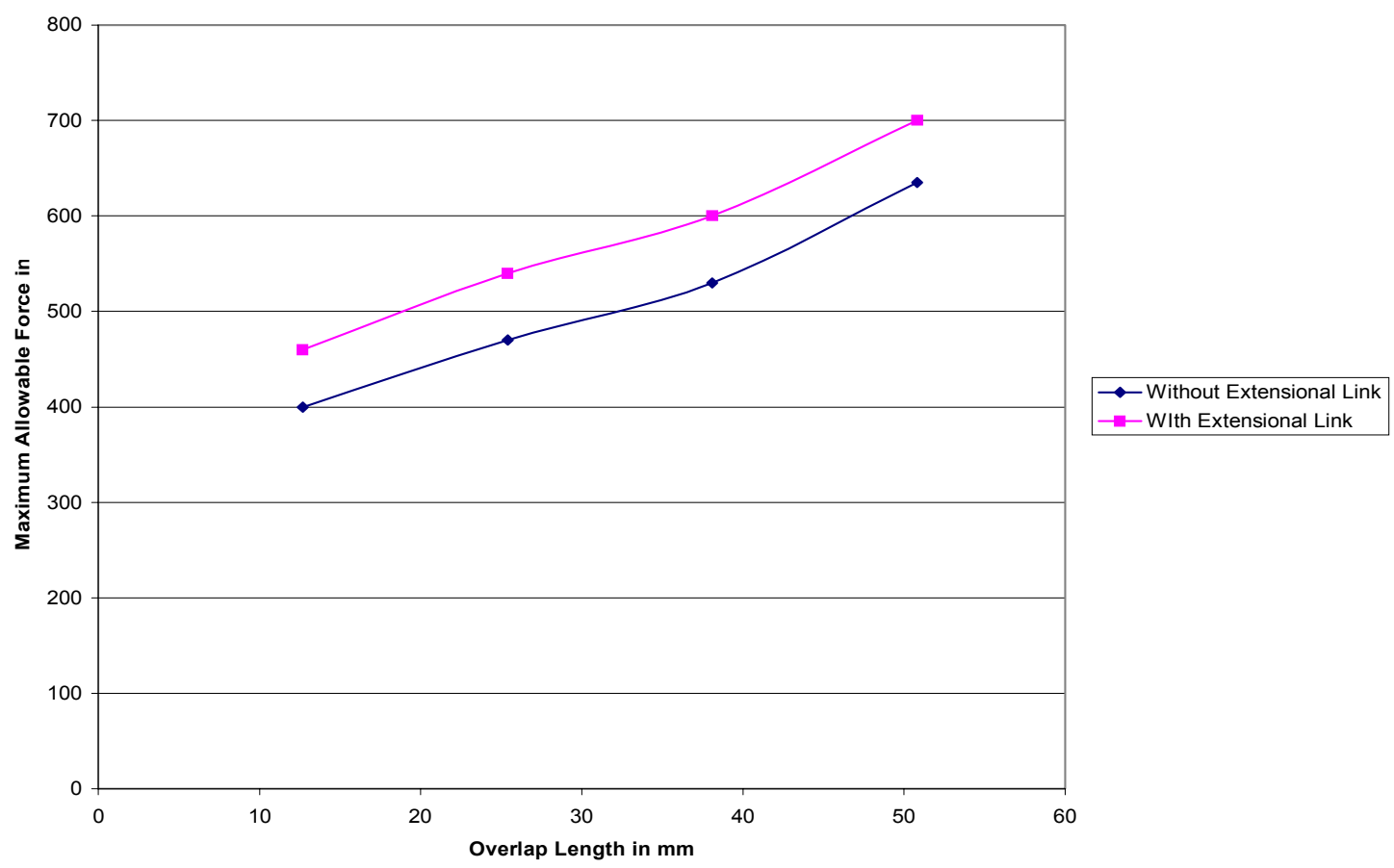

Fig 6.15: Effect of Extensional Link on Maximum Load that can be Transferred Through a Single Lap Bonded Joint 


\section{CHAPTER 7: CONCLUSIONS AND FUTURE WORK}

\subsection{Conclusions}

The parametric analysis of the double lap joint reveals the effects of several factors on the structural behavior of the joint. The following conclusions can be made from the analysis on the present model:

- The extensional link reduces the shear stress along the adhesive and the decrease in the shear stress increases with the increase in the stiffness of the extensional link.

- As the thickness of the adhesive increases the shear stress becomes uniform along the length of the overlap and the maximum shear stress decreases with increase in the thickness of the adhesive.

- The effect of the stiffness of the extensional link is more for small overlap lengths. Thus, it can be concluded that a lot of material can be saved and small overlap length can be used with a stiff extensional link in order to get a better joint.

- The effect of extensional link becomes negligible as the adhesive becomes stiffer. Thus the extensional link is more useful for weak adhesives.

- The finite element modeling is very useful for joints with complexity and our closed form model and the finite element model tally with each other.

- The shear stress at the free edge in the adhesive is reduced due to the tapering in the outer adherend.

- The spew fillet reduces the shear stress in the adhesive throughout the bond length when compared to the joint without spew fillet.

- The maximum shear stress in the spew fillet is not at the edge of the free end of the adhesive instead it is a very low at that point.

- The maximum allowable force increases with the increase in the stiffness of the extensional link in the single lap bonded joint even when the adhesive is stiff.

- The effect of extensional link is negligible on the maximum allowable force for the double lap bonded joints when the adhesive is stiff. 
- As the stiffness of the adherends increases the maximum shear in the adhesive decreases in the double lap bonded joint.

- As the thickness of the adhesive increases the maximum shear in the adhesive decreases.

\subsection{Future Work}

In the present research work, the inner and outer adherends, adhesives and extensional link which are the main components of the double lap bonded joints are considered to be elastic and isotropic but even the same finite element model can be extended to any material property such as orthotropic or viscoelastic material for any of the components.

Also the work can be extended for more complex shapes of the inner and outer adherends. A zigzag shape can also be considered for the adherends and the adhesives at the bond line.

Surface roughness of the adherends can also be considered as one of the factors for the parametric study. Friction between the adhesive and the adherends in the bonded joint can also be included in the model by using contact elements in the finite element analysis.

A 3D finite element model can also be built which is more realistic and an inclusion can be added at the bond line in order to check the possibility of increasing the overall stiffness of the joint. 


\section{REFERENCES}

[1] Jacky Prucz, Analysis of Design tradeoffs for Passively Damped Structural Joints, J. Spacecraft, Vol. 23, No. 6, Nov.-Dec. 1986.

[2] Hart-Smith, L.J., Adhesive-Bonded Double-Lap joints, NASA CR-112235, Jan. 1973.

[3] Jacky Prucz, Analytical and Experimental Methodology for Evaluating Passively Damped Structural Joints, 1985.

[4] Alexander Bogdanovich and Indrajith Kizhakkethara, Three dimensional finite element analysis of adhesively bonded plates, 1984.

[5] Kum Cheol Shin and Jung Ju Lee, Tensile load-bearing capacity of co-cured double lap joints, Journal of Adhesion Science, Vol.14, No.12, pp. 1539-1556, 2000.

[6] Shiuh-Chuan Her, Stress analysis of adhesively-bonded lap joints, Composite Structures, Vol. 47, pp. 673-678, 1999.

[7] L.Tong, A non-linear analysis of adhesive bonded symmetric lap joints using shear lag model, Transactions of the CSME, Vol. 24, No.1B, 2000.

[8] A.G.Zink, R.W.Davidson, R.B.Hanna, Finite Element Modeling of Double Lap Wood Joints, J. Adhesion, Vol. 56, pp. 217-228, 1996.

[9] K.D. potter, F.J. Guild , H.J. Harvey, M.R. Wisnom, R.D. Adams,Understanding and control of adhesive crack propagation in bonded joints between carbon fibre composite adherends I. Experimental., International Journal of Adhesion and Adhesives, 21, pp. 445-443, 2001.

[10] K.D. potter, F.J. Guild, H.J. Harvey, M.R. Wisnom, R.D. Adams, Understanding and control of adhesive crack propagation in bonded joints between carbon fibre composite adherends II. Finite element analysis.

[11] Guoqiang Li, Su-Seng Pang, Eyassu Woldesenbet, Michael A. Stubblefield, Patrick F. Mensah, Samuel I. Ibekwe., Investigation of prepeg bonded composite single lap joint. [12] Shiuh-Chuan Her, Stress analysis of adhesively-bonded lap joints, Composite Structures, 47, pp. 673-678, 1999.

[13] Yehia A. Bahei-El-Din, George J. Dvorak, New Designs of adhesive joints for thick composite laminates, Composite Science and Technology, 61, pp. 19-40, 2001. 
[14] Naveen Rastogi, Som R. Soni, Arvind Nagar, A combined analytical and experimental study of design parameters in composite bonded joints, AIAA-98-1882. [15] AdamsAdams, R. D., Structural adhesive joints in engineering, 1984.

[16] Tong. L and Steven G.P, Analysis and Design of Structural Bonded Joints, Kluwer Academic Publishers, 1999.

[17] Yin, Yong., Analysis of Adhesive-bonded double-lap joints, Thesis (M.S.), South Dakota School of Mines and Technology, Rapid City, 1992.

[18] Ever J.Barbero, Introduction to Composite Materials Design, Taylor \& Francis, Inc., 1998.

[19] Swanson Analysis Systems, Inc, Ansys User's Manual, Version 6.1, Electronic. 


\section{APPENDIX 1}

MAPLE PROGRAM FOR THE CLOSED FORM MODEL OF THE DOUBLE LAP JOINT WITH EXTENSIONAL LINK

$>$ restart;

$>\mathrm{P}:=4.45$

$$
\mathrm{P}:=4.45
$$

$>\mathrm{E}:=107593$;

$$
\mathrm{E}:=107593
$$

$>$ Es:=15748;

$$
\text { Es := } 15748
$$

$>$ ti:=3.8;

$$
\text { ti }:=3.8
$$

$>$ ts:=1.19;

$$
\text { ts }:=1.19
$$

$>\mathrm{t}:=3.8$;

$$
\mathrm{t}:=3.8
$$

$>\mathrm{tv}:=0.5$

$$
\text { tv }:=.5
$$

$>1:=50.8$;

$$
1:=50.8
$$

$>1 \mathrm{~s}:=12.7$;

$$
\text { ls := }=12.7
$$

$>\mathrm{G}:=41.38$ 


$$
\mathrm{G}:=41.38
$$

$>\mathrm{b}:=38.1$

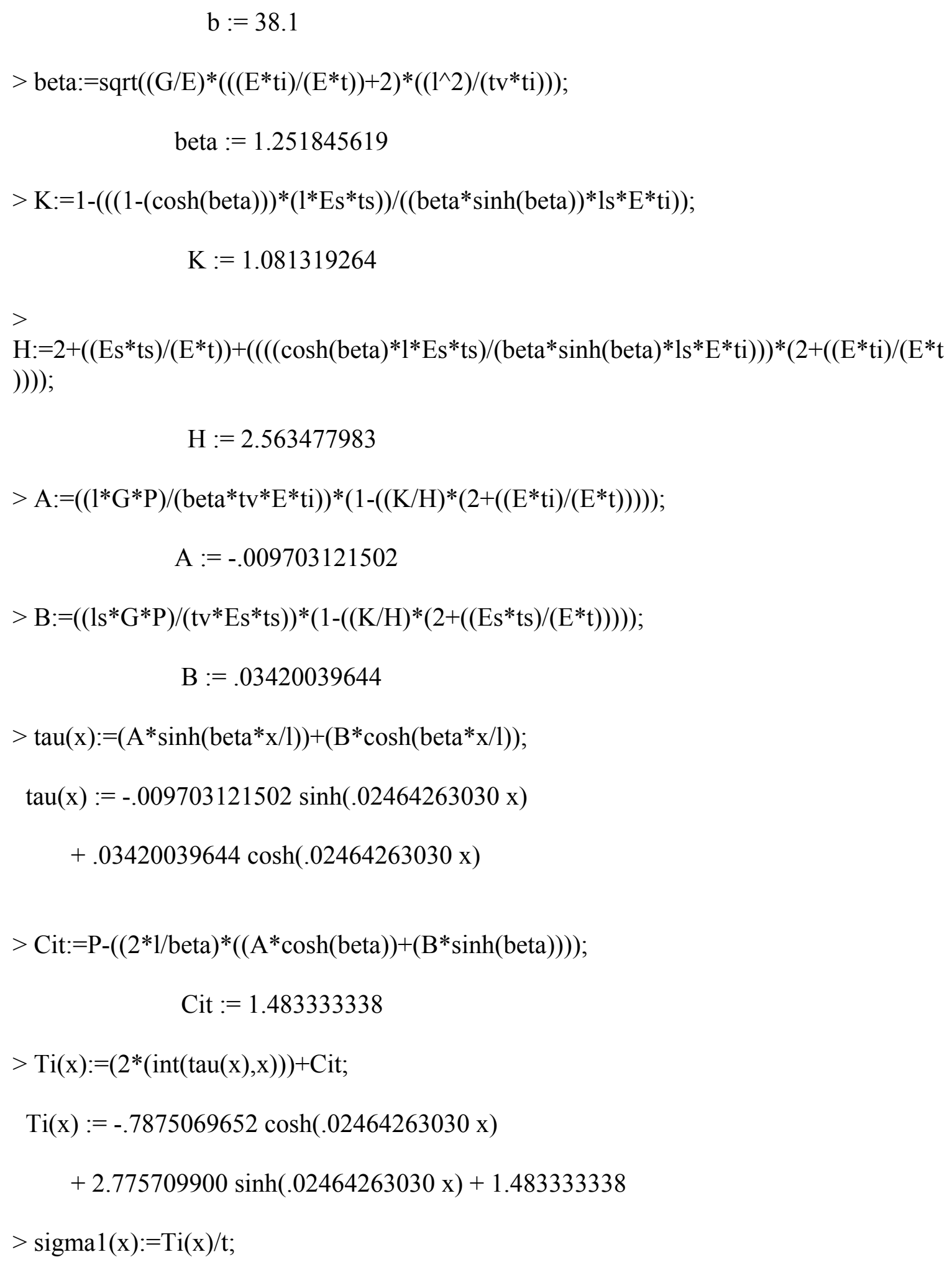




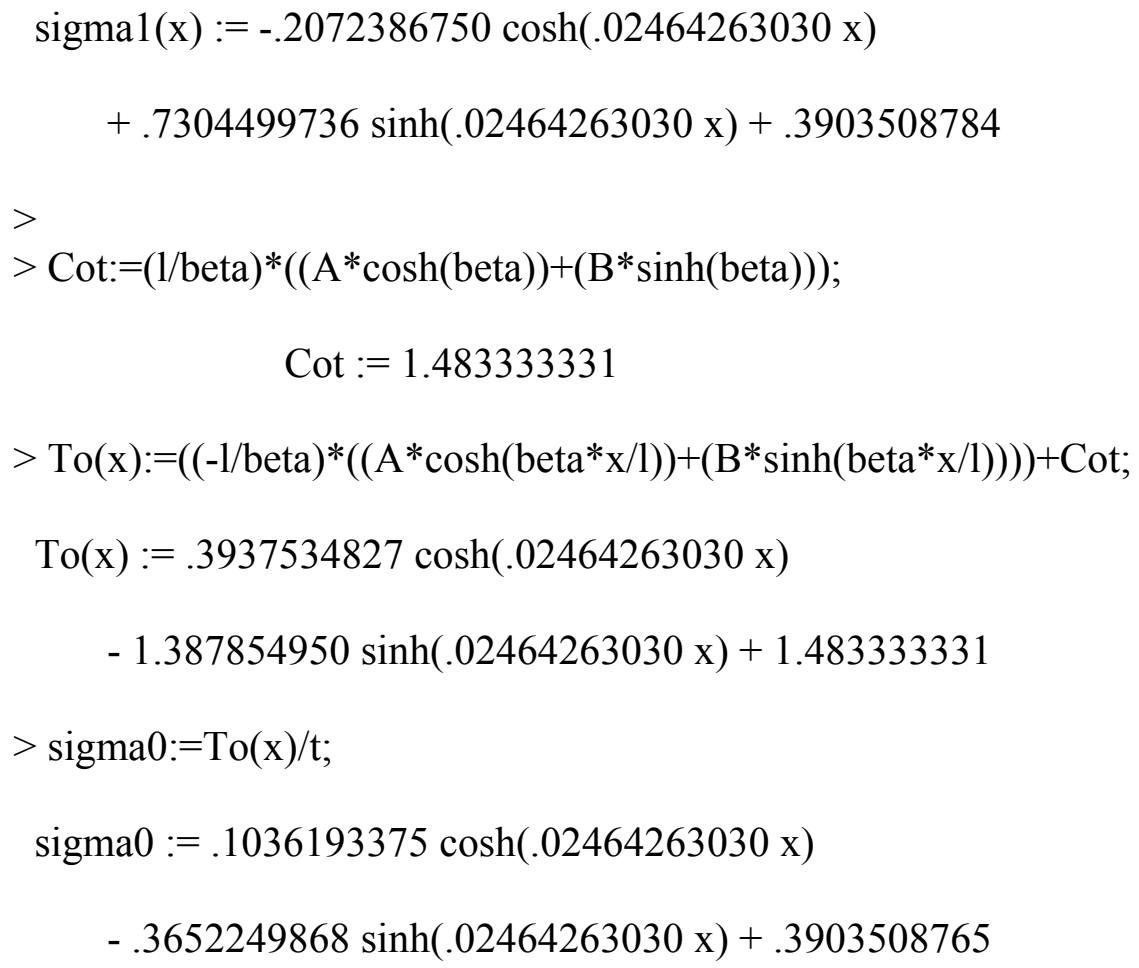

